\title{
Dietary cholesterol supplementation to a plant-based diet suppresses the complete pathway of cholesterol synthesis and induces bile acid production in Atlantic salmon (Salmo salar L.)
}

\author{
Trond M. Kortner ${ }^{1 *}$, Ingemar Björkhem ${ }^{2}$, Aleksei Krasnov ${ }^{3}$, Gerrit Timmerhaus $^{3}$ and Åshild Krogdahl ${ }^{1}$ \\ ${ }^{1}$ Department of Basic Sciences and Aquatic Medicine, NMBU School of Veterinary Science, Oslo, Norway \\ ${ }^{2}$ Division of Clinical Chemistry, Department of Laboratory Medicine, Karolinska University Hospital, Huddinge, Sweden \\ ${ }^{3}$ Nofima AS, Ås, Norway \\ (Submitted 4 November 2013 - Final revision received 17 December 2013 - Accepted 27 January 2014 - First published online 17 March 2014)
}

\section{Abstract}

Plants now supply more than $50 \%$ of protein in Norwegian salmon aquafeeds. The inclusion of plant protein in aquafeeds may be associated with decreased lipid digestibility and cholesterol and bile salt levels, indicating that the replacement of fishmeal with plant protein could result in inadequate supplies of cholesterol in fish. A reduction in feed efficiency, fish growth and pathogen resistance is often observed in parallel to alterations in sterol metabolism. Previous studies have indicated that the negative effects induced by plant components can be attenuated when diets are supplemented with cholesterol. The present study evaluated the effects of dietary cholesterol supplementation (1.5\%) in Atlantic salmon fed a plant-based diet for $77 \mathrm{~d}$. The weights of body, intestines and liver were recorded and blood, tissues, faeces, chyme and bile were sampled for the evaluation of effects on growth, nutrient utilisation and metabolism, and transcriptome and metabolite levels, with particular emphasis on sterol metabolism and organ structure and function. Cholesterol supplementation did not affect the growth or organ weights of Atlantic salmon, but seemed to promote the induction of cholesterol and plant sterol efflux in the intestine while suppressing sterol uptake. Cholesterol biosynthesis decreased correspondingly and conversion into bile acids increased. The marked effect of cholesterol supplementation on bile acid synthesis suggests that dietary cholesterol can be used to increase bile acid synthesis in fish. The present study clearly demonstrated how Atlantic salmon adjusted their metabolic functions in response to the dietary load of cholesterol. It has also expanded our understanding of sterol metabolism and turnover, adding to the existing, rather sparse, knowledge of these processes in fish.

\section{Key words: Fish feeds: Plant ingredients: Cholesterol: Bile}

In recent years, research efforts have been focused on finding alternative protein sources for use in aquafeeds as fishmeal availability has stagnated and market prices have increased ${ }^{(1)}$. As a result, compound feeds used in aquaculture today contain increasing amounts of plant protein, replacing fishmeal $^{(2,3)}$. However, the use of plant protein sources for carnivorous fish species such as salmonids is still met with challenges as certain plant components may interfere with fish health and welfare ${ }^{(4)}$. It is well known that increasing levels of plant protein in fish diets will reduce the levels of dietary cholesterol. Traditional marine-based diets will provide at least $1 \mathrm{~g}$ cholesterol $/ \mathrm{kg}$ of feed, whereas plant products contain virtually no cholesterol ${ }^{(5)}$. Additionally, certain plant components and antinutritional factors (phytosterols and saponins) may impair cholesterol uptake from the intestinal lumen and thereby further decrease plasma cholesterol levels ${ }^{(4,6)}$. Accordingly, inclusion of plant protein in fish feeds typically results in decreased lipid digestibility, hypocholesterolaemia and reduced bile salt levels ${ }^{(7-12)}$. A reduction in feed efficiency, fish growth and pathogen resistance is often observed in parallel to alterations in sterol metabolism ${ }^{(13-15)}$.

Cholesterol is not considered to be an essential nutrient in fish primarily owing to the fact that vertebrates can synthesise cholesterol from acetate. The potential for cholesterol synthesis may vary, however, and the possibility that fish have less capacity than mammals to compensate for a low intake of cholesterol with increased synthesis must be considered. The relatively few reported studies on cholesterol supplementation to aquafeeds suggest that the effects of dietary cholesterol depend on the nature of the basal diet. Dietary cholesterol supplementation (1.0\%) to fishmeal-based diets has been found to not affect growth in Atlantic salmon ${ }^{(16)}$, hybrid striped bass ${ }^{(17)}$ and Japanese flounder ${ }^{(18)}$. By contrast, cholesterol supplementation has been observed to significantly

Abbreviations: $\operatorname{abcg} 5$, ATP-binding cassette G5; C4, 7 $\alpha$-hydroxy-4-cholesten-3-one; CYP7A1, cytochrome P450 7A1; FA, fatty acids; HMGCR, 3-hydroxy3-methylglutaryl-CoA reductase; qRT-PCR, real-time PCR; $l x r$, liver X receptor. 
improve growth when included in soyabean meal-based diets of channel catfish ${ }^{(19)}$, turbot ${ }^{(15,20)}$ and rainbow trout ${ }^{(21)}$ or when included in Salicornia bigelovii seed meal of Nile tilapia ${ }^{(22)}$. Furthermore, cholesterol supplementation $(0 \cdot 9-1 \cdot 2 \%)$ to a soyabean meal-based diet has also been found to improve the immune response and resistance to Aeromonas bydrophila in rainbow trout ${ }^{(23)}$. This suggests that the negative effects induced by plant components can be attenuated by dietary supplementation with cholesterol. Therefore, cholesterol supplementation may be beneficial when fish are fed plant protein-based diets.

Cholesterol is an integral component of cell membranes and also serves as a precursor to important metabolites such as steroid hormones and bile acids. At present, the regulation of cholesterol metabolism and homeostasis in fish is largely unknown. Cholesterol can be obtained from the diet or synthesised de novo, and the conversion of cholesterol into bile acids represents a major route for the elimination of excess cholesterol from the body. The synthesis of cholesterol from acetyl-CoA involves more than twenty enzymatic reaction steps, but the presumed rate-limiting step is the synthesis of mevalonate by 3-hydroxy-3-methylglutaryl-CoA reductase (HMGCR). The rate-limiting step in primary bile acid synthesis, and thereby cholesterol catabolism, is mediated by cholesterol $7 \alpha$-hydroxylase (CYP7A1). Recent studies in fish have reported that high levels of supplemental cholesterol (1-1.5\%) induce CYP7A1 activity and reduce HMGCR activity $^{(15,21)}$. This indicates that excess levels of cholesterol lead to the suppression of cholesterol biosynthesis and increased conversion into bile acids. On the other hand, several studies $^{(8,14,24,25)}$ have reported that high inclusion levels of plant protein stimulate cholesterol biosynthesis, suggesting that the replacement of fishmeal with plant protein sources may result in an inadequate supply of cholesterol in fish. Another crucial factor for controlling cholesterol homeostasis is the uptake of dietary cholesterol from the intestinal lumen ${ }^{(26)}$, but essentially nothing is known about these mechanisms in fish.

Plants now supply more than $50 \%$ of protein in Norwegian salmon aquafeeds, but, to our knowledge, there are no reported studies on cholesterol supplementation to plantbased feeds in Atlantic salmon. The present study is a part of a larger experiment investigating dietary supplementation to plant meal-based diets in Atlantic salmon. In the present study, we evaluated the effects of dietary cholesterol supplementation (1.5\%) in Atlantic salmon fed a plant-based diet for $77 \mathrm{~d}$. A comprehensive analytical package was used to shed light on the essentially unexplored pathways of sterol metabolism in fish. The weights of body, intestines and liver were recorded and blood, tissues, faeces, intestinal chyme and bile were sampled for the evaluation of effects on growth, nutrient utilisation and metabolism, and transcriptome and metabolite levels, with particular emphasis on sterol metabolism and organ structure and function. Tissues of interest for the molecular studies were the liver, which is the main organ for cholesterol and bile acid synthesis, and the pyloric caeca, which is the major site of lipid absorption in Atlantic salmon. We hypothesised that dietary supplementation of $1.5 \%$ cholesterol to a plant-based diet would lead to alterations in Atlantic salmon sterol levels that would be reflected in transcriptional and biochemical signatures, as well as growth and nutrient utilisation.

\section{Materials and methods}

\section{Experimental animals, diet and sampling}

The present study was conducted in compliance with laws regulating experimentation with live animals in Norway as overseen by the Norwegian Animal Research Authority (FDU). The feeding trial was carried out at the Nofima research station at Sunndalsøra, Norway. Atlantic salmon (Salmo salar L.) post-smolts of the Sunndalsøra breed with a mean weight of 362 (SD 95) g were weighed, pit tagged and randomly allocated to four cylindrical fibreglass tanks (200 litres, thirty-five fish/tank) with flow-through seawater $(6-71 / \mathrm{min})$. In the trial, two replicate tanks per diet were used. Water temperature varied between 7 and $14^{\circ} \mathrm{C}$. Oxygen content and salinity of the outlet water were monitored to secure saturation above $85 \%$ and stability, respectively. A $24 \mathrm{~h}$ lighting regimen was employed during the experimental period. The fish were weighed individually during allocation to the experimental units to ensure similar biomass in all the tanks. The fish were fed continuously and approximately $20 \%$ in excess of the expected feed intake a plantbased diet with and without 1.5\% cholesterol (Table 1) using automatic disc feeders. Feed intake was not recorded. Diets were formulated to contain $41 \%$ crude protein and $30 \%$ lipid (DM basis). They were supplemented with a standard vitamin and micro-mineral premix and limiting essential amino acids (lysine and methionine) as necessary to provide required amounts as suggested by the NRC guidelines ${ }^{(27)}$. The diets also contained $50 \mathrm{mg} / \mathrm{kg}$ yttrium oxide as an inert marker for the calculation of nutrient apparent digestibilities. The formulation and chemical analysis results of the control diet are given in Table 1 . Feed was produced by extrusion at the BioMar A/S production facility in Brande, Denmark. Diets were extruded with a feed pellet size of $6 \mathrm{~mm}$. The feeding trial was carried out for $77 \mathrm{~d}$. Tank sampling and fish sampling were conducted randomly. To ensure intestinal exposure to the diets, only fish with digesta throughout the intestinal tracts were sampled. A total of fifteen fish were sampled from each tank and killed by anaesthetisation with tricaine methanesulfonate (MS-222) followed by a sharp blow to the head. Blood was sampled by venepuncture of the caudal vein of ten fish per tank. Blood was collected in vacutainers containing lithium heparin and stored on ice until centrifugation. Plasma was separated and immediately frozen in liquid $\mathrm{N}_{2}$ and stored at $-80^{\circ} \mathrm{C}$ until analysis. After blood withdrawal, the fish were dissected to remove the viscera. Bile was collected directly from the gall bladder of ten fish per tank using a syringe, transferred to Eppendorf tubes, frozen in liquid $\mathrm{N}_{2}$ and stored at $-80^{\circ} \mathrm{C}$ until analysis. Intestinal contents (digesta) were collected from the pyloric intestine, mid-intestine and distal intestine. The pyloric and distal intestine contents were divided into proximal (PI1 and DI1, respectively) and distal (PI2 and DI2, respectively) portions. 
Table 1. Formulation and chemical analysis results of the control diet*

\begin{tabular}{|c|c|}
\hline Ingredients & $g / 100 \mathrm{~g}$ \\
\hline SA SP Sara Rousing (Super Prime) $†$ & 5.00 \\
\hline Nordic LT 94 fishmealł & 5.00 \\
\hline Soya $60 \%(\mathrm{SPC}) \S$ & 19.03 \\
\hline Maize gluten|| & $15 \cdot 00$ \\
\hline Pea protein 509 & 13.00 \\
\hline Dehulled beans ${ }^{\star *}$ & $14 \cdot 00$ \\
\hline Wheat glutent† & 1.97 \\
\hline 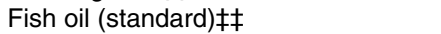 & $7 \cdot 67$ \\
\hline Rapeseed oil§§ & $17 \cdot 60$ \\
\hline Monocalcium phosphate\|\|\| & 1.82 \\
\hline Lys \|\| & $0 \cdot 81$ \\
\hline Met|\|\| & 0.32 \\
\hline Thr|\|\| & $0 \cdot 11$ \\
\hline Barox (antioxidant)|||| & 0.03 \\
\hline Norwegian biovitamin mix\|\| & 0.30 \\
\hline Yttrium oxide ๆ ๆ & 0.05 \\
\hline Lucantin Pink CWD 10\%\|\|\| & 0.04 \\
\hline \multicolumn{2}{|l|}{ Chemical analysis results } \\
\hline DM (\%) & $95 \cdot 0$ \\
\hline Ash (\%) & $5 \cdot 0$ \\
\hline Fat $(\%)$ & $29 \cdot 2$ \\
\hline Protein (\%) & $40 \cdot 4$ \\
\hline D Protein (\%) & $36 \cdot 0$ \\
\hline DE (MJ/kg) & $20 \cdot 3$ \\
\hline GE (MJ/kg) & 24.4 \\
\hline \multicolumn{2}{|l|}{ Cholesterol (g/kg) } \\
\hline Control diet & 0.8 \\
\hline Cholesterol diet & $15 \cdot 7$ \\
\hline
\end{tabular}

SPC, soya protein concentrate; DE, digestible energy; GE, gross energy.

* The cholesterol diet was identical to the control diet, except for $1.5 \%$ cholesterol. Chemical analysis was conducted only for the control diet, but cholesterol content analysis was conducted for both the diets.

† Supplied by Köster Marine Proteins $\mathrm{GmbH}$.

¥ Supplied by Norsildmel AS.

§ Supplied by Selecta S/A, Avenida Jamel Ceilio, 2496 - 12th region.

\| Supplied by Cargill Nordic.

I Supplied by DLG Food Grain.

** Supplied by HC Handelscenter.

†† Supplied by Roquette.

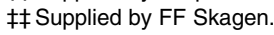

$\S \S$ Supplied by Emmelev.

|||| Supplemented to meet the requirements.

१ ๆ Inert marker for the evaluation of nutrient digestibility.

Intestinal contents were frozen in liquid $\mathrm{N}_{2}$ and stored at $-80^{\circ} \mathrm{C}$ until analysis. Pyloric caeca, mid-intestine and distal intestine, and liver were sampled from five fish per tank for histology and RNA analysis. For histology, tissue samples were fixed in $10 \%$ neutral buffered formalin ( $4 \%$ formaldehyde) for $24 \mathrm{~h}$ and subsequently transferred to $70 \% \mathrm{EtOH}$ for storage until processing. For RNA analysis, samples were rinsed in sterile saline and submerged in RNAlater ${ }^{\circledR}$ and stored at $4^{\circ} \mathrm{C}$ for $24 \mathrm{~h}$ and then at $-40^{\circ} \mathrm{C}$ until analysis. The remaining fish in each tank were stripped for faeces and continued to be fed the feed for an additional week during which they were stripped again. Faecal samples were pooled and frozen until analysis.

\section{RNA extraction}

Total RNA was extracted from liver and pyloric caeca samples (approximately $30 \mathrm{mg}$ ) using TRIzol ${ }^{\circledR}$ reagent (Invitrogen) and purified with PureLink (Invitrogen) including an on-column DNAse treatment according to the manufacturer's protocol. The integrity of the RNA samples was verified using the
2100 Bioanalyzer in combination with RNA Nano Chip (Agilent Technologies), and RNA purity and concentrations were measured using the NanoDrop ND-1000 Spectrophotometer (NanoDrop Technologies). RNA samples with integrity number $>8$ were included in the gene expression analysis. Total RNA samples were stored at $-80^{\circ} \mathrm{C}$ until use.

\section{Microarray analyses}

Microarray analyses were carried out on liver samples. A twocolour design was used, where individual fish samples (five in each study group, two to three fish from each tank duplicate) were labelled with fluorescent $\mathrm{Cy} 3$ and hybridised against a common reference sample labelled with fluorescent Cy5. The common reference sample consisted of a pool of ten individual fish fed a fishmeal-based diet. Nofima's Atlantic salmon 15k oligonucleotide microarray SIQ-6 (GEO Omnibus GPL16555) was obtained from Agilent Technologies and, unless indicated otherwise, the reagents and equipment were also from the same source. RNA amplification and labelling were performed using the Two-Colour Low Input Quick Amp Labelling Kit and the Gene Expression Hybridisation Kit was used for the fragmentation of labelled RNA. The amount of total RNA used in each reaction was $200 \mathrm{ng}$. After overnight hybridisation in an oven $\left(17 \mathrm{~h}\right.$ at $65^{\circ} \mathrm{C}$ and rotation speed of $10 \mathrm{rpm}$ ), arrays were washed with Gene Expression Wash Buffers 1 and 2 and scanned with GenePix 4100A (Molecular Devices). GenePix Pro 6.0 was used for spotto-grid alignment, spot quality assessment, feature extraction and quantification. Subsequent data analyses were carried out using the bioinformatic system STARS ${ }^{(28)}$. After filtration of low-quality spots flagged by GenePix, Lowess normalisation of $\log _{2}$-expression ratios was performed. Genes that passed quality control in at least four samples per group were included in subsequent analyses. Differentially expressed genes were selected based on the following criteria: fold difference $>1.6$ and $P<0.05$ ( $t$ test). The enrichment of Gene Ontology and Kyoto Encyclopedia of Genes and Genomes (KEGG) terms in the list of differentially expressed genes was assessed with Yates' corrected $\chi^{2}$ using all the probes that passed quality control as a reference; enriched terms corresponding to at least five differentially expressed genes were selected. Complete data files were deposited at the National Center for Biotechnology Information (NCBI) Gene Expression Omnibus with accession no. GSE51887.

\section{Quantitative real-time PCR}

Hepatic gene expression was quantified by quantitative realtime PCR (qRT-PCR) to validate microarray analysis results and to examine particular genes of interest in detail. In addition, qRT-PCR was used for the quantification of genes related to lipid and sterol metabolism in pyloric caeca. Assays were carried out according to the MIQE (Minimum Information for Publication of Quantitative Real-Time PCR Experiments) standards ${ }^{(29)}$ on ten fish from each diet group (five fish from each tank duplicate). First-strand complementary DNA was synthesised using $0.8 \mu \mathrm{g}$ of total RNA from all samples using 
Superscript III (Invitrogen) in $20 \mu \mathrm{l}$ reaction mixtures and primed with oligo $(\mathrm{dT})_{20}$ primers according to the manufacturer's protocol. Negative control tests were carried out in parallel by omitting RNA or enzyme. The obtained complementary DNA was diluted 1:10 before use and stored at $-20^{\circ} \mathrm{C}$. The qRT-PCR primers were designed based on the literature or using Primer3 (http://frodo.wi.mit.edu/primer3/). Primer details are given in online supplementary Table S1. All primer pairs gave a single band pattern for the expected amplicon of interest in all the reactions. PCR efficiency for each gene assay was determined using 10-fold serial dilutions of randomly pooled complementary DNA. The expression of individual gene targets was analysed using the LightCycler 480 (Roche Diagnostics). Each $10 \mu$ l DNA amplification reaction mixture contained $2 \mu \mathrm{l}$ PCR-grade water, $2 \mu \mathrm{l}$ of $1: 10$ diluted complementary DNA template, $5 \mu \mathrm{l}$ of LightCycler 480 SYBR Green I Master (Roche Diagnostics) and $0.5 \mu \mathrm{l}$ (final concentration $500 \mathrm{~nm}$ ) of each forward and reverse primer. Each sample was assayed in duplicate, including a no-template control. The three-step qRT-PCR programme included an enzyme activation step at $95^{\circ} \mathrm{C}(5 \mathrm{~min})$ and forty cycles of $95^{\circ} \mathrm{C}(10 \mathrm{~s}), 60^{\circ} \mathrm{C}(10 \mathrm{~s})$ and $72^{\circ} \mathrm{C}(15 \mathrm{~s})$. Quantification cycle $\left(C_{\mathrm{q}}\right)$ values were calculated using the second derivative method. To confirm amplification specificity, the PCR products from each primer pair were subjected to melting curve analysis and visual inspection after each run by agarose gel electrophoresis. For target gene normalisation, $a c t b$ ( $\beta$-actin), ef1a (elongation factor $1 \alpha$ ), gapdh (glyceraldehyde-3-phosphate dehydrogenase) and rnapolII (RNA polymerase II) were evaluated for use as reference genes by ranking relative gene expression according to their overall $\mathrm{CV}$ and their interspecific variance, as described previously ${ }^{(30)}$. For pyloric caeca samples, gapdh was used as a normalisation factor, whereas the geometric average of gapdh, $a c t b$ and rnapolII was used for liver samples. The relative expression of target genes was calculated using the ${ }^{\Delta \Delta} C_{\mathrm{t}}$ method ${ }^{(31)}$.

\section{Chemical analysis}

Diet and faecal samples were analysed for DM (after heating at $105^{\circ} \mathrm{C}$ for $16-18 \mathrm{~h}$ ), ash (by combusting at $550^{\circ} \mathrm{C}$ to constant weight), nitrogen (crude protein) (using the semi-micro Kjeldahl method, Kjeltec Auto System; Tecator), fat (by diethyl ether extraction in a Fosstec analyser (Tecator) after $\mathrm{HCl}$ hydrolysis), starch (measured as glucose after hydrolysis by $\alpha$-amylase (Novo Nordisk $\mathrm{A} / \mathrm{S}$ ) and amyloglucosidase (Boehringer Mannheim $\mathrm{GmbH}$ ), followed by determination of glucose levels using the 'Glut-DH method' (Merck)), gross energy using the Parr 1271 Bomb calorimeter (Parr) and yttrium by inductively coupled plasma MS as described by Refstie et $a l{ }^{(32)}$. The levels of amino acids in the diet samples were determined using a Biochrom 30 amino acid analyser following the EC Commission Directive 98/64/EC (1999) after hydrolysis in $6 \mathrm{M}-\mathrm{HCl}$ for $23 \mathrm{~h}$ at $110^{\circ} \mathrm{C}$. The levels of tryptophan and tyrosine were determined after basic hydrolysis. For analyses of fatty acid (FA) composition, lipid extracts were transmethylated over night with 2,2-dimethoxypropane, methanolic $\mathrm{HCl}$ and benzene at room temperature, as described by Mason \&
Waller $^{(33)}$ and Hoshi et al. ${ }^{(34)}$. The methyl esters of the FA thus formed were separated in a gas chromatograph (Hewlett Packard 6890) with a split injector, a SGE BPX70 capillary column (length $60 \mathrm{~m}$ and internal diameter $0.25 \mathrm{~mm}$ and thickness of the film $0 \cdot 25 \mu \mathrm{m}$ ) and a flame ionisation detector, and the results were analysed using the HP ChemStation software. Helium was used as the carrier gas. The injector and detector temperatures were $280^{\circ} \mathrm{C}$. The oven temperature was raised from 50 to $180^{\circ} \mathrm{C}$ at a rate of $10^{\circ} \mathrm{C} / \mathrm{min}$ and then raised to $240^{\circ} \mathrm{C}$ at a rate of $0.7^{\circ} \mathrm{C} / \mathrm{min}$. The relative quantity of each $\mathrm{FA}$ present was determined by measuring the area under the chromatograph peak corresponding to that FA.

\section{Plasma variables and bile salt levels in bile and intestinal contents}

Plasma samples were analysed for NEFA, cholesterol, total TAG and glucose following standard procedures at the Central Laboratory of the Norwegian School of Veterinary Science (NVH), Oslo. The levels of total intestinal bile salts were measured in pooled freeze-dried gastrointestinal contents from the PI1, PI2, MI, DI1, and DI2 portions. The levels of bile salts were determined using the enzyme cycling amplification/thionicotinamide-aderine dinucleotide (Thio-NAD) method (Inverness Medical) in the ADVIA ${ }^{\circledR} 1650$ Chemistry System (Siemens Healthcare Diagnostics, Inc.) at the Central Laboratory of $\mathrm{NVH}$. In bile taken directly from the gall bladder, the levels of glycine- and taurine-conjugated bile acids were determined using HPLC-MS/MS by a modification of the method described by Tagliacozzi et al. ${ }^{(35)}$ using ${ }^{2} \mathrm{H}$-labelled glycine derivatives of bile acids as internal standards. In some cases, the levels of bile acids were also determined by isotope dilution and combined GC-MS after deconjugation as described by Björkhem \& $\mathrm{Falk}^{(36)}$. The plasma levels of oxysterol were determined by isotope dilution and combined GC-MS after hydrolysis as described by Dzeletovic et $a l{ }^{(37)}$. The levels of sitosterol and campesterol were determined by isotope dilution and combined GC-MS after hydrolysis as described by Acimovic et $a l .{ }^{(38)}$. The levels of lathosterol were determined by isotope dilution MS as described by Lund et $a l^{(39)}$. The levels of $7 \alpha$-hydroxy-4-cholesten-3-one (C4) were determined by isotope dilution and combined HPLC-MS as described by Lövgren-Sandblom et al. ${ }^{(40)}$. Plasma lipoprotein profiles were determined employing size exclusion chromatography and measurements of cholesterol and TAG on-line using microlitre sample volumes as described by Parini et al. ${ }^{(41)}$.

\section{Histology}

Samples used for histology were processed using standard histological techniques and stained with haematoxylin and eosin at the NVH. Pyloric caeca and liver tissue samples were evaluated by light microscopy in a randomised order.

\section{Calculations}

Crude protein content was calculated as $\mathrm{N} \times 6 \cdot 25$. Thermal growth coefficient (TGC) was calculated as follows: 
Table 2. Mean final body weights, thermal growth coefficients (TGC), specific growth rates (SGR) and apparent digestibilities (Mean values with their standard errors)

\begin{tabular}{lcccc}
\hline & $\begin{array}{c}\text { Control } \\
\text { diet group }\end{array}$ & $\begin{array}{c}\text { CH } \\
\text { diet group }\end{array}$ & $\begin{array}{c}\text { Pooled } \\
\text { SEM }\end{array}$ & $P^{*}$ \\
\hline Final body weights (g) & 709 & 706 & 24 & 0.93 \\
$\quad$ TGC & 2.54 & 2.56 & 0.08 & 0.89 \\
SGR & 0.87 & 0.87 & 0.02 & 0.80 \\
Apparent & & & & \\
$\quad$ digestibilities (\%) & & & & \\
Fat & 95.7 & 94.5 & $0.28 \dagger$ & $\dagger$ \\
Protein & 90.0 & 90.1 & 0.30 & 0.84 \\
Starch & 75.6 & 77.5 & 1.08 & 0.35 \\
Taurine & -46 & -162 & 30 & 0.11 \\
\hline
\end{tabular}

$\mathrm{CH}$, cholesterol.

* $P$ values obtained in two-sided Student's $t$ test are given

† Statistical test could not be conducted due to one missing value. The mean value reported for fat digestibility is the pooled means with their standard errors for all the twenty-three tanks included in the feeding trial.

$$
\mathrm{TGC}=(\mathrm{FBW} 1 / 3-\mathrm{IBW} 1 / 3) \times\left(\Sigma D^{\circ}\right)-1,
$$

where IBW and FBW are the initial and final body weights (tank means) and $\Sigma D^{\circ}$ is the thermal sum (feeding days $\times$ average temperature in ${ }^{\circ} \mathrm{C}$ ). Organosomatic indices were calculated as the percentages of the weight of the organ in relation to body weight. Apparent digestibility (AD) was estimated by the indirect method using $\mathrm{Y}_{2} \mathrm{O}_{3}$ as an inert marker and calculated as follows:

$$
\mathrm{AD}=100-\left[100 \times\left(M_{\text {feed }} / M_{\text {faeces }}\right) \times\left(N_{\text {faeces }} / N_{\text {feed }}\right)\right],
$$

where $M_{\text {feed }}$ and $M_{\text {faeces }}$ are the percentage concentration of the inert marker $\left(\mathrm{Y}_{2} \mathrm{O}_{3}\right)$ in the feed and faeces, respectively, and $N_{\text {feed }}$ and $N_{\text {faeces }}$ are the percentage concentration of a nutrient in the feed and faeces, respectively. Nutrient retention (retentions of crude protein, individual amino acids and energy) was calculated as follows:

$$
\begin{aligned}
\text { Nutrient retention }= & 100 \times\left[\left(\mathrm{FBW} \times \mathrm{C}_{1}\right)-\left(\mathrm{IBW} \times \mathrm{C}_{0}\right)\right] \\
& \times\left[F \times C_{\text {diet }}\right]-1,
\end{aligned}
$$

where $C_{\text {diet }}$ is the nutrient content in the diets and $C_{0}$ and $C_{1}$ are the initial and final nutrient contents in the fish.

\section{Statistical analyses}

Statistical analyses were carried out using GraphPad Prism version 6.03 (GraphPad Software, Inc.). The feeding trial had a completely randomised design, and cholesterol inclusion was evaluated as the class variable. Data were analysed using a two-sided Student's $t$ test with a significance level of $P<0 \cdot 05$, unless otherwise indicated. qRT-PCR data are presented as $P<0.05$ or NS $(P>0.05)$; for all other data, the actual $P$ values are reported.

\section{Results}

Fish growth, organ indices, nutrient digestibilities and histology

Data on fish growth and nutrient digestibilities are given in Table 2. Cholesterol supplementation did not affect the growth rates or macronutrient digestibility. Nor did it affect the digestibility of individual FA or amino acids (data not shown). A trend towards reduced taurine 'digestibility' was observed, indicating increased endogenous output of taurine-containing compounds to the intestine. Organ indices and histomorphology of the pyloric caeca and liver were not affected (data not shown).

\section{Blood plasma biochemistry}

Data on blood plasma biochemistry are given in Table 3 . Cholesterol supplementation to the plant-based diet resulted in the expected, marked elevation of plasma cholesterol levels. On the other hand, cholesterol supplementation reduced blood plasma TAG levels. The pattern and distribution of lipids in the three lipoprotein fractions (HDL, LDL and VLDL) were similar to those in rodents in the control group. Thus, most of the cholesterol and TAG were distributed in the HDL fraction. There was a pronounced change in the pattern and distribution of lipids in the plasma of fish fed the cholesterol-containing diet (Table 3 and Fig. 3). In these fish, most of the increase in cholesterol levels seemed to occur in the LDL fraction, showing a 10-fold increase, whereas the levels in the HDL fraction seemed to be unaffected. The levels of TAG in the HDL fraction were reduced, and most of the TAG were distributed in the LDL and VLDL fractions. Cholesterol supplementation did not affect plasma bile salt levels. No effects of cholesterol supplementation were

\begin{tabular}{|c|c|c|c|c|}
\hline & $\begin{array}{c}\text { Control } \\
\text { diet group }\end{array}$ & $\begin{array}{c}\mathrm{CH} \\
\text { diet group }\end{array}$ & $\begin{array}{l}\text { Pooled } \\
\text { SEM }\end{array}$ & $P^{\star}$ \\
\hline Total CH (mmol/l) & $8 \cdot 3$ & $24 \cdot 3$ & 0.5 & $<0.001$ \\
\hline VLDL-CH† & 0.1 & 0.2 & & \\
\hline LDL-CH† & $1 \cdot 3$ & $13 \cdot 9$ & & \\
\hline $\mathrm{HDL}-\mathrm{CH} \dagger$ & $7 \cdot 5$ & $7 \cdot 6$ & & \\
\hline Total TAG (mmol/l) & $3 \cdot 3$ & $1 \cdot 6$ & $0 \cdot 16$ & $<0.001$ \\
\hline VLDL-TAG† & 0.5 & $0 \cdot 2$ & & \\
\hline LDL-TAG† & $1 \cdot 0$ & 0.8 & & \\
\hline HDL-TAG† & $3 \cdot 2$ & 0.7 & & \\
\hline Bile salts $(\mu \mathrm{mol} / \mathrm{l})$ & 20 & 18 & 4 & 0.79 \\
\hline Lathosterol $(\mu \mathrm{g} / \mathrm{ml})$ & $3 \cdot 8$ & $2 \cdot 21$ & 0.19 & $<0.001$ \\
\hline $\mathrm{C} 4(\mu \mathrm{g} / \mathrm{ml})$ & 0.01 & 0.16 & 0.01 & $<0.001$ \\
\hline Sitosterol $(\mu \mathrm{g} / \mathrm{ml})$ & 74 & 7 & $4 \cdot 6$ & $<0.001$ \\
\hline Campesterol ( $\mu \mathrm{g} / \mathrm{ml})$ & 188 & 21 & 12 & $<0.001$ \\
\hline \multicolumn{5}{|l|}{ Oxysterols (ng/ml)† } \\
\hline $7 \alpha-\mathrm{Hydroxy}-\mathrm{CH}$ & 130 & 1419 & & \\
\hline $7 \beta-H y d r o x y-C H$ & 37 & 123 & & \\
\hline 7-Keto-hydroxy-CH & 101 & 226 & & \\
\hline 24-Hydroxy-CH & $2 \cdot 2$ & $6 \cdot 4$ & & \\
\hline 25-Hydroxy-CH & 5 & 29 & & \\
\hline 27-Hydroxy-CH & 21 & 51 & & \\
\hline
\end{tabular}
observed on plasma glucose or free FA levels (data not

Table 3. Mean blood plasma variables

(Mean values with their standard errors ( $n 10$ fish per diet group))

$\mathrm{CH}$, cholesterol; C4, 7 $\alpha$-hydroxy-4-cholesten-3-one.

${ }^{*} P$ values obtained in two-sided Student's $t$ test are given.

† Lipoprotein and oxysterol profiles were measured in a pooled sample of ten fish per diet group. CV for the different assays, i.e. the analytical variance, as estimated by analysing a control sample over ten consecutive days, were as follows: VLDL-CH: $8.1 \%$; LDL-CH: $3.4 \%$; HDL-CH: $5.0 \%$; VLDL-TAG: $13.1 \%$; LDLTAG: $10.5 \%$; HDL-TAG: $9.7 \%$. CV for all oxysterol assays were $<8 \%$, except for 25 -hydroxy-CH assay $(11 \%)^{(37)}$ 
shown). The cholesterol-containing diet decreased the circulating lathosterol levels, indicative of decreased cholesterol synthesis in the liver. C4 is an intermediate in bile acid synthesis, and the plasma level of this oxysterol has been shown to be a marker of bile acid synthesis in humans ${ }^{(42)}$. Thus, it seemed likely that the high levels of $\mathrm{C} 4$ in the cholesterol-supplemented group reflected the markedly increased synthesis of bile acids as a consequence of the dietary load of cholesterol. The levels of the precursor of $\mathrm{C} 4$, $7 \alpha$-hydroxycholesterol, were also substantially increased in the plasma of fish fed the cholesterol-containing diet. Cholesterol supplementation resulted in increased plasma levels of $7 \beta$-hydroxycholesterol and 7-keto-cholesterol as well as 24-, 25- and 27-hydroxycholesterol. Cholesterol supplementation also seemed to abolish the intestinal uptake of plant sterols, as evidenced by the markedly reduced plasma levels of sitosterol and campesterol.

\section{Gall bladder and chyme bile acid levels}

Data on gall bladder and chyme bile acid levels are given in Table 4. No significant differences in total bile acid levels or total conjugated bile acid levels were found between the diet groups. The majority of bile acids in the gallbladder bile were conjugated; the only unconjugated bile acid found was cholic acid, which was detected at low concentrations. However, cholic acid levels were significantly increased after cholesterol supplementation. The taurine-conjugated bile acids were the predominant form of bile acids found in the bile, with taurocholic acid being the predominant individual bile acid. While no diet effect was observed on taurocholic acid levels, taurochenodeoxycholic acid levels were higher in the bile of fish fed the cholesterol-containing diet. The glycineconjugated bile acids were detected at very low concentrations,

Table 4. Mean bile acid levels in the gall bladder and gut content (Mean values with their standard errors, $n 10$ fish per group)

\begin{tabular}{lcccc}
\hline & $\begin{array}{c}\text { Control } \\
\text { diet group }\end{array}$ & $\begin{array}{c}\mathrm{CH} \\
\text { diet group }\end{array}$ & $\begin{array}{c}\text { Pooled } \\
\text { SEM }\end{array}$ & $P^{*}$ \\
\hline Gall bladder bile (mg/ml) & & & & \\
$\quad$ Total bile acids & 117 & 126 & 5.8 & 0.31 \\
$\quad$ Total conjugated & 117 & 125 & 5.8 & 0.33 \\
$\quad$ Total unconjugated & $<0.1$ & 0.4 & 0.1 & 0.04 \\
$\quad$ (cholic acid) & & & & \\
$\quad$ Taurine conjugated & 117 & 125 & 5.8 & 0.33 \\
Taurocholic acid & 110 & 106 & 5.6 & 0.59 \\
Taurochenodeoxycholic & 6 & 19 & 1.5 & $<0.001$ \\
$\quad$ acid & & & & \\
Taurodeoxycholic acid & $<0.1$ & 0.2 & 0.03 & 0.003 \\
Glycine conjugated & $<0.1$ & $<0.1$ & - & - \\
Total bile in the gut & & & & \\
$\quad$ content (mg/g DM) & 355 & 306 & 52 & 0.59 \\
PI1 & 262 & 272 & 43 & 0.88 \\
PI2 & 218 & 185 & 36 & 0.61 \\
MI & 74 & 105 & 10 & 0.22 \\
DI1 & 10 & 14 & 2 & 0.34 \\
DI2 & & &
\end{tabular}

$\mathrm{CH}$, cholesterol; PI1, pyloric intestine portion 1; PI2, pyloric intestine portion 2; MI, mid-intestine; DI1, distal intestine portion 1; DI2, distal intestine portion 2. ${ }^{\star} P$ values obtained in two-sided Student's $t$ test are given. and there were no differences in the levels between the diet groups. In the intestinal chyme, bile salt levels decreased gradually from the proximal to the distal parts. No statistically significant differences in the levels in any of the intestinal regions were observed between the diet groups.

\section{Intestinal gene expression}

The pyloric caeca expression profiles of key genes involved in lipid and sterol transport and biosynthesis and transcriptional control are shown in Fig. 1. Except for a significant downregulation of FA transporter $c d 36$ (cluster of differentiation 36) expression, cholesterol supplementation exerted limited effects on the expression of genes involved in fat absorption and turnover and lipoprotein synthesis (fatp (FA transport protein), fabp2a1 (FA-binding protein 2a1), mgat $2 a$ (monoacylglycerol acyltransferase 2-A), mtp (microsomal triglyceride transfer protein) and apo). By contrast, cholesterol supplementation markedly increased the mRNA levels of the basolateral (abca1) and apical (abcg5) cholesterol efflux transporters and decreased the mRNA levels of NiemannPick C1-like 1 (npc1l1), presumably responsible for cholesterol uptake from the intestinal lumen. There was an increase in the expression of acyl-CoA cholesterol acyltransferase (acat), witch catalyses the intracellular esterification of cholesterol. There was an increase in the expression of taurine transporter slc6a6 in fish fed the cholesterol-containing diet, whereas no effects were observed on the expression of bmgcr. Cholesterol supplementation resulted in a differential expression of several nuclear receptors with important regulatory roles in fat and sterol homeostasis. There was an increase in the expression of oxysterol-activated transcription factor liver $\mathrm{X}$ receptor $(l x r)$ as well as sterol element-binding protein 1 (srebp1) and ppar $\alpha$. By contrast, cholesterol supplementation led to a decrease in srebp 2 mRNA levels.

\section{Hepatic gene expression}

The microarray analysis and qRT-PCR data were closely correlated (Pearson's correlation coefficient: 0.90, $P<0 \cdot 0001$ ). In the microarray analyses, 322 entities were found to be to be differentially expressed between the two diet groups (fold change $>1.6, P<0.05$ ). A search for enriched Gene Ontology terms and KEGG pathways in the list of differentially expressed genes was carried out for rapid screening of the thematic associations of the transcriptional response (Table 5). As expected, the results indicated that cholesterol supplementation led to alterations in sterol biosynthesis pathways (steroid, steroid hormone and terpenoid synthesis). This observation was reflected in the individual gene expression signatures (see Table 6 for microarray analysis results and Fig. 1 for qRT-PCR data). The effect of cholesterol supplementation was evident, as we observed a strong and concerted downregulation of the expression of nearly all enzymes involved in cholesterol biosynthesis (Fig. 2) as well as the master regulator srebp2. The microarray analysis results indicated the downregulation of the expression of genes that take part in biotransformation and enhance the solubility of steroids 
(a)

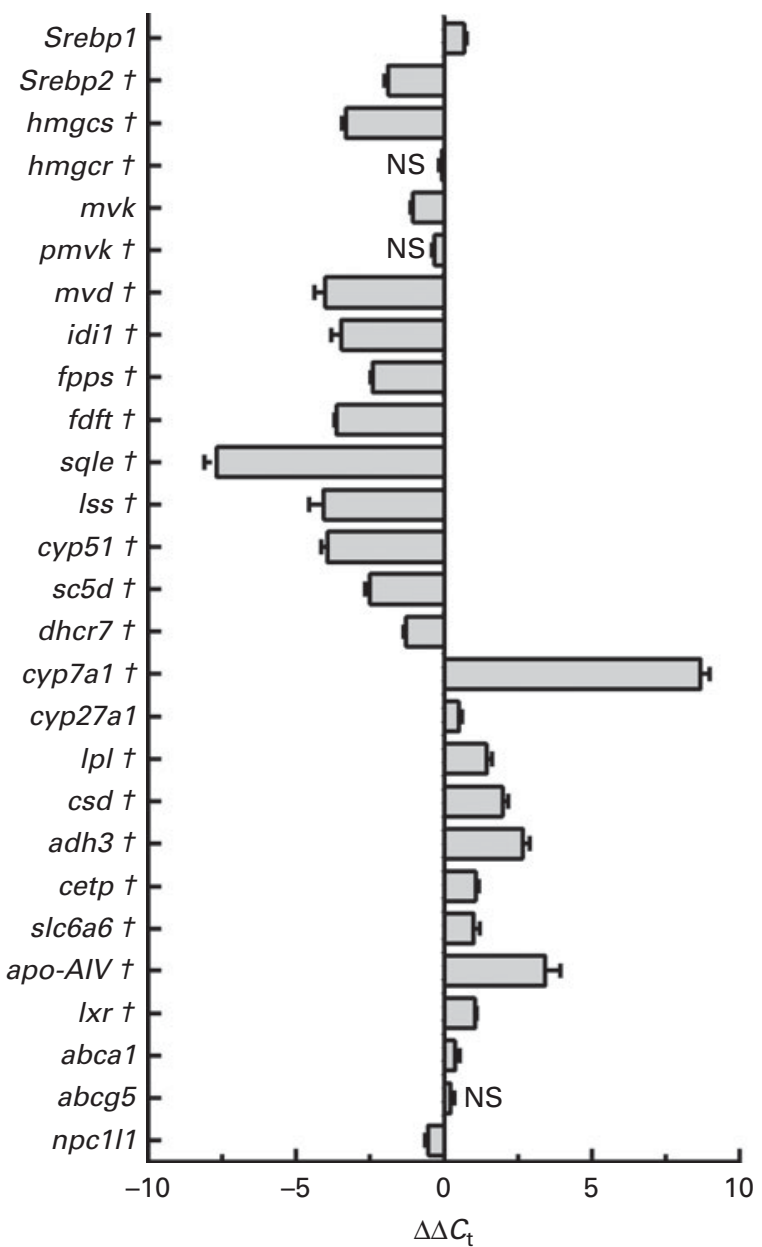

(b)

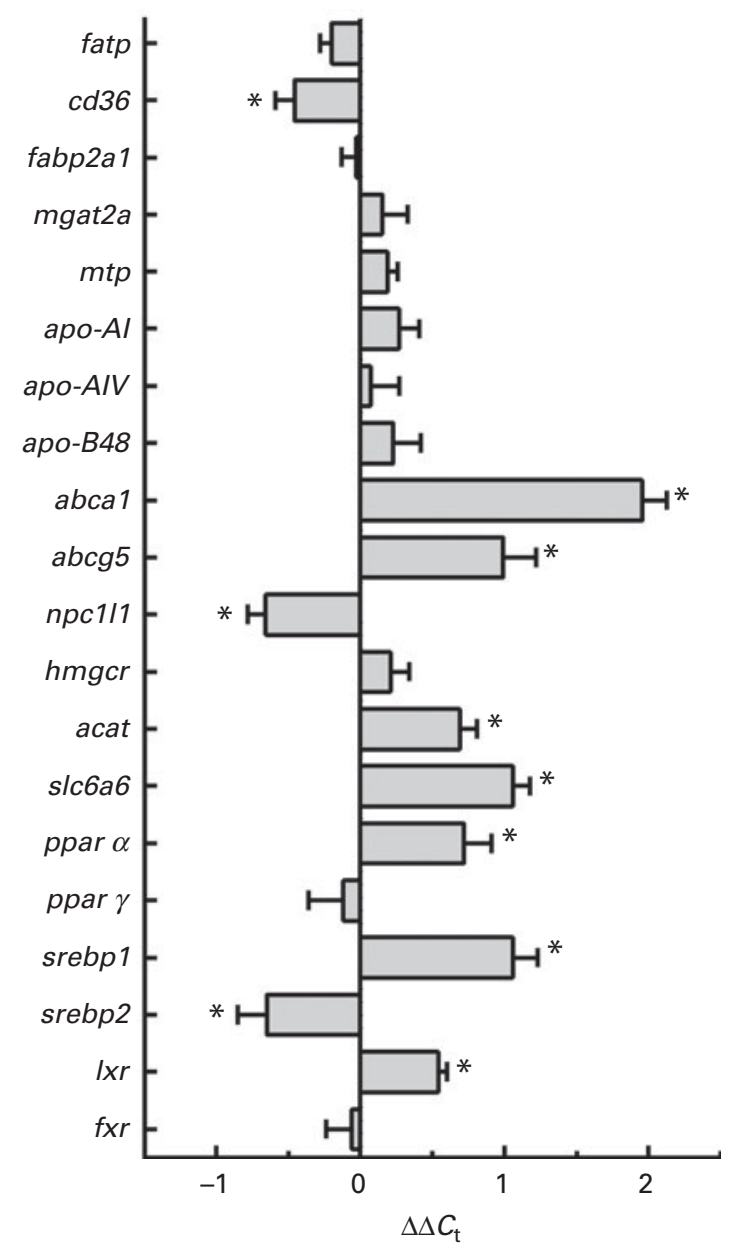

Fig. 1. Gene expression profiling of (a) liver and (b) pyloric caeca samples by quantitative real-time PCR (qRT-PCR). Values are mean ${ }^{\Delta \Delta} C_{t}$, with their standard errors represented by bars ( $n 10$ fish per group). Mean values obtained for liver samples of the cholesterol-supplemented group were significantly different from those of the control group, except for those marked with NS $(P<0.05)$. * Mean values obtained for pyloric caeca samples of the cholesterol-supplemented group were significantly different from those of the control group, $(P<0.05)$. $†$ Gene expression was also measured by microarray analyses. See online Supplementary Table S1 for a list of names and abbreviations.

(sts (steroid sulfatase, microsomal isozyme), gstt1b (glutathione $S$-transferase $\theta 1$ ) and cyp1a1 (cytochrome P450 1A1)). Furthermore, increased conversion of cholesterol into bile acids was indicated by an astonishing 400-fold increase in cyp7a1 expression after cholesterol supplementation. Bile production was also indicated by the up-regulation of the expression of cyp27a1 (cytochrome P450 27A1), two isoforms of the taurine transporter slc6a6, $a b c c 2$ (multidrug resistance-associated protein 2), a mediator of hepatobiliary excretion of diverse organic anions, and cysteine sulfinate decarboxylase (csd), which is involved in taurine biosynthesis. The induction of alcohol dehydrogenase $3(a d h 3)$ expression is also worth mentioning, as this enzyme catalyses the oxidation of intermediary alcohols of the shunt pathway of mevalonate metabolism, which provides a biochemical link between cholesterol and leucine metabolism ${ }^{(43)}$. Furthermore, the expression of $l x r$ was induced together with that of its obligate partner retinoid $\mathrm{X}$ receptor ( $r x r)$, whereas that of $a b c g 5$ was stable. The expression of several lipoproteins was induced in parallel to that of
Table 5. Functional Gene Ontology (GO) categories and KEGG (Kyoto Encyclopedia of Genes and Genomes) pathways enriched with genes that were differentially expressed (DEG) in response to cholesterol supplementation

\begin{tabular}{lcc}
\hline GO categories and KEGG pathways & Features $^{\star}$ & $P \dagger$ \\
\hline Steroid biosynthesis & $7 / 15$ & $<0.001$ \\
Steroid hormone biosynthesis & $5 / 30$ & 0.031 \\
Terpenoid backbone biosynthesis & $5 / 29$ & 0.004 \\
Amino acid metabolic process & $5 / 24$ & 0.01 \\
PPAR signalling pathway & $7 / 73$ & 0.046 \\
Glutathione metabolism & $7 / 53$ & 0.005 \\
Cell cycle & $13 / 94$ & $<0.001$ \\
DNA replication & $7 / 46$ & 0.001 \\
Microtubule & $16 / 66$ & $<0.001$ \\
Mitosis & $12 / 63$ & $<0.001$ \\
p53 signalling pathway & $8 / 57$ & 0.001 \\
\hline
\end{tabular}

*Numbers of genes among DEG and on the microarray platform. †Yates' corrected $\chi^{2}$. 
Table 6. Differentially expressed genes involved in steroid, bile and lipid metabolism (hepatic microarray analysis)*

\begin{tabular}{|c|c|c|c|c|}
\hline GenBank accession & Name & Symbol & Fold change & $P+$ \\
\hline EG840055 & Isopentenyl-diphosphate $\Delta$-isomerase 1 & idi1 & -6.98 & 0.011 \\
\hline DY717161 & Squalene synthetase & $f d f t \pm$ & -6.45 & 0.005 \\
\hline 209156003 & Diphosphomevalonate decarboxylase & $m v d \ddagger$ & $-6 \cdot 05$ & 0.012 \\
\hline 209155565 & Farnesyl pyrophosphate synthetase & fppsł & -5.92 & 0.004 \\
\hline DY731118 & Cytochrome P450 family 51 & cyp51a1 & $-5 \cdot 27$ & 0.003 \\
\hline 117498019 & Isopentenyl-diphosphate $\Delta$-isomerase 1 & idi1 & $-4 \cdot 16$ & 0.028 \\
\hline CF752841 & Sterol regulatory element-binding protein 2 & srebp2‡ & -3.31 & 0.012 \\
\hline DY694469 & Lamin B receptor & tm7sf2 & $-3 \cdot 30$ & 0.016 \\
\hline AM402497 & 3-Hydroxy-3-methylglutaryl-coenzyme A synthase & hmgcsł & $-3 \cdot 25$ & 0.038 \\
\hline DW573009 & 7-Dehydrocholesterol reductase & dhcr7ł & -1.83 & 0.047 \\
\hline CB504999 & Steroid sulfatase, microsomal isozyme & sts & -1.78 & 0.039 \\
\hline CB503922 & 7-Dehydrocholesterol reductase & dhcr7 & -1.67 & 0.036 \\
\hline 209731043 & Glutathione $S$-transferase $\theta 1$ & gstt $1 b$ & -1.77 & 0.044 \\
\hline BT045666 & Cytochrome P450 1A1 & cyp1a1 & -1.90 & 0.020 \\
\hline 209155257 & Cytochrome P450 3A27 & сурза27 & 1.87 & 0.044 \\
\hline EG763020 & Nuclear receptor subfamily 1 , group $\mathrm{H}$, member 3 & Ixt & 1.96 & 0.012 \\
\hline 89878241 & Sodium- and chloride-dependent taurine transporter 2 & slc6a6b & $2 \cdot 23$ & 0.008 \\
\hline EG809777 & Cholesteryl ester transfer protein & cetp $\ddagger$ & 3.12 & $<0.001$ \\
\hline 223648941 & Taurine transporter & slc6a6bł & 3.15 & 0.002 \\
\hline DY703201 & Cysteine sulfinate decarboxylase-like protein 1 & $\operatorname{csd} 1$ & 4.63 & 0.001 \\
\hline 377783949 & Cysteine sulfinate decarboxylase-like protein 2 & $\operatorname{csd} 2 \ddagger$ & $5 \cdot 02$ & $<0.001$ \\
\hline 223648313 & Cytochrome P450 7A1 & cyp7a1‡ & 13.4 & 0.008 \\
\hline DY719572 & Multidrug resistance-associated protein 2 & $a b c c 2$ & 1.77 & 0.006 \\
\hline EG929557 & Alcohol dehydrogenase class 3 & adh3‡ & $6 \cdot 01$ & 0.003 \\
\hline DY692060 & RXR 1 & $r \times r 1$ & 1.68 & 0.006 \\
\hline EG942280 & Retinol dehydrogenase 12-like & hsd17b7 & $-6 \cdot 30$ & 0.013 \\
\hline TC112002 & RXR 2 & $r \times r 2$ & -2.83 & 0.001 \\
\hline 209154595 & Lathosterol oxidase & sc5d\# & -3.85 & 0.001 \\
\hline 209737903 & PHS1 & ptplb & -2.86 & 0.019 \\
\hline DW531881 & PUFA elongase elov12 & elovl2 & $-2 \cdot 68$ & $<0.001$ \\
\hline 209736321 & Acyl-CoA-binding protein & $d b i$ & $-2 \cdot 14$ & 0.010 \\
\hline 209155867 & Peroxisomal biogenesis factor 7 & $w d r 77$ & -1.96 & 0.018 \\
\hline EG830046 & Epoxide hydrolase 2 & pla2g7 & -1.75 & 0.001 \\
\hline DY725316 & Fatty acyl-CoA hydrolase & sasb & 1.72 & 0.027 \\
\hline DW566815 & 1-O-Acylceramide synthase precursor & Icat & 1.80 & 0.038 \\
\hline 209154667 & 1-Acyl-sn-glycerol-3-phosphate acyltransferase- $\gamma$ & agpat3 & 1.92 & 0.007 \\
\hline EG785823 & Apolipoprotein-L3 & apol3 & 2.51 & 0.017 \\
\hline DW532957 & Apolipoprotein A-IV precursor & apoaiv & $2 \cdot 83$ & 0.005 \\
\hline CU066928 & Acetoacetyl-CoA synthetase & aacs & -5.00 & 0.017 \\
\hline DQ423473 & CCAAT/enhancer-binding protein- $\gamma$ & cebpg & 1.78 & 0.011 \\
\hline 223672612 & CCAAT/enhancer-binding protein- $\beta 2$ & cebpb & 2.06 & $<0.001$ \\
\hline ВT072598 & Adipophilin & adfp & $2 \cdot 27$ & 0.002 \\
\hline
\end{tabular}

* Values are mean fold change observed in the cholesterol diet-fed group in comparison with those in the control diet-fed group.

t $P$ values obtained in the $t$ test are given.

$\ddagger$ Genes were confirmed by quantitative real-time PCR (see Fig. 2).

lipoprotein lipase $(l p l)$ and cholesteryl ester transfer protein (cetp), which facilitates the transport of cholesterol esters and TAG between lipoproteins. The expression of a suite of genes encoding enzymes involved in lipid metabolism was downregulated in concert with that of peroxisomal biogenesis factor $7(w d r 77)$. However, there was an increase in the expression of three regulators of adipocyte differentiation (cebpg (CCAAT/enhancer-binding protein- $\gamma$ ), cebpb (CCAAT/ enhancer-binding protein- $\beta 2$ ) and $a d f p$ (adipophilin)).

Cholesterol supplementation seemed to affect cell proliferation and cell-cycle progression as reflected by the enrichment of terms related to DNA replication, mitosis and cell cycle (Table 5). This was manifested in individual gene signatures by a concerted down-regulation of the expression of genes related to DNA replication, nucleotide biosynthesis, and chromosome maintenance, spindle formation, and chromosome segregation and mitosis (Table 7). This was in line with the increased expression of the negative regulators of cell proliferation tob1 (Tob1) and cdkn1c (cyclin-dependent kinase inhibitor 1C). The effect of cholesterol supplementations on the hepatic expression of immune genes was relatively small (Table 8). The up-regulation of the expression of C1q components of the classical complement pathways together with that of fcer $1 \mathrm{~g}$ (high-affinity Ig receptor subunit- $\gamma$ ), which binds to opsonised antibodies, is worth mentioning. The expression of four mediators of inflammation including that of three isoforms of lect $2 l$ (leukocyte cellderived chemotaxin 2-1) was down-regulated.

\section{Discussion}

In the present study, dietary cholesterol supplementation (1.5\%) to a plant-based diet was found to not affect Atlantic salmon growth, macronutrient digestibility, organ indices, or hepatic and intestinal histomorphology. Cholesterol supplementation has been reported to significantly improve fish 


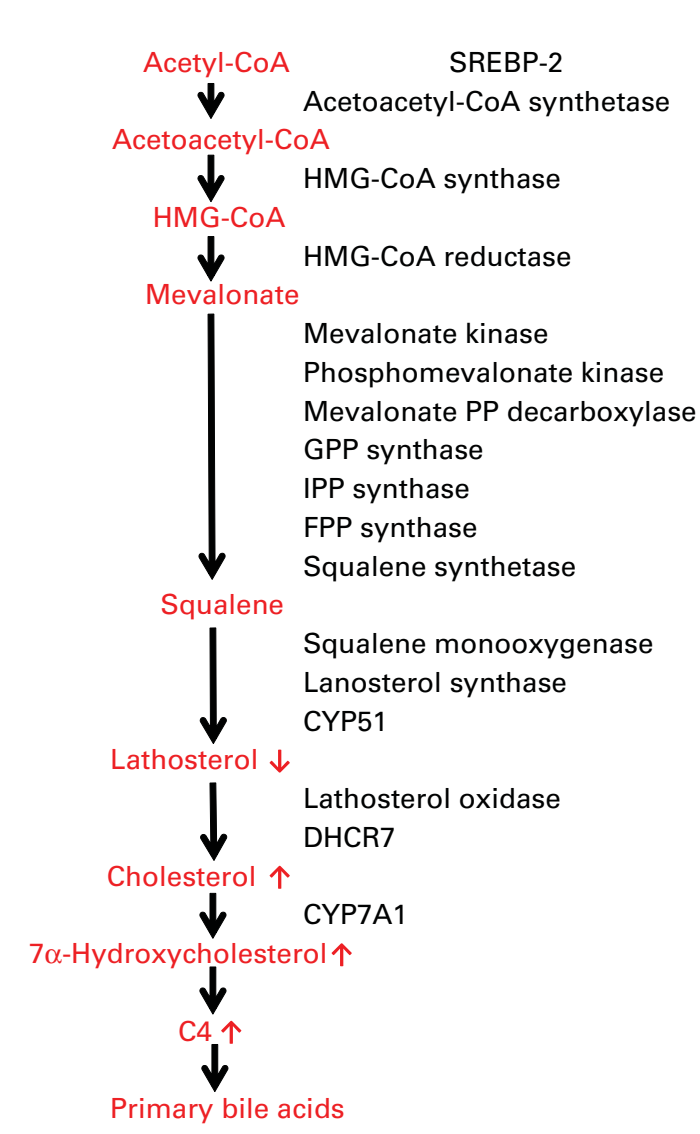

\begin{tabular}{|c|c|}
\hline MA & qPCR \\
\hline-3.31 & -3.72 \\
\hline-5.00 & - \\
\hline & \\
\hline-3.25 & -9.90 \\
\hline & \\
\hline$-1.01^{*}$ & $-1.06^{*}$ \\
\hline & \\
\hline- & -2.06 \\
\hline- & $-1.25^{*}$ \\
\hline-6.05 & -16.2 \\
\hline $0.22^{*}$ & - \\
\hline-6.98 & -11.1 \\
\hline-5.92 & -5.32 \\
\hline-6.45 & -12.3 \\
\hline & \\
\hline$-3.87^{*}$ & -203 \\
\hline$-1.68^{*}$ & -16.7 \\
\hline-5.27 & $-15 \cdot 4$ \\
\hline & \\
\hline-3.85 & -5.69 \\
\hline-1.83 & -2.41 \\
\hline & \\
\hline 13.45 & 410 \\
\hline & \\
\hline
\end{tabular}

\begin{tabular}{|l|c|c|c|c|c|c|}
\hline Down $>32$ & $32-5 \cdot 7$ & $5 \cdot 6-2 \cdot 6$ & $2 \cdot 5-1 \cdot 7$ & $<1 \cdot 3$ & $5 \cdot 7-32$ & Up $>32$ \\
\hline
\end{tabular}

Fig. 2. Regulation of hepatic cholesterol biosynthesis by dietary cholesterol supplementation. Major metabolic intermediates are shown in red font and genes are shown in black font. Microarray (MA) and quantitative real-time PCR (qPCR) values are mean fold change observed in the cholesterol-supplemented group in comparison with those in the control group. * Mean values were not significantly different $(P>0.05)$. SREBP-2, sterol regulatory element-binding protein 2 ; HMGCoA, 3-hydroxy-3-methylglutaryl-CoA; GPP, geranyl diphosphate; IPP, isopentenyl diphosphate; FPP, farnesyl pyrophosphate; C4, 7 $\alpha$-hydroxy-4-cholesten-3-one; CYP51, cytochrome P450 family 51; DHCR7, 7-dehydrocholesterol reductase; CYP7A1, cytochrome P450 7A1.

growth when included in diets containing high levels of soyabean meal ${ }^{(15,19-21)}$. The lack of an effect in the present study is most probably due to the inclusion of more refined plant protein sources such as soya protein concentrate and wheat gluten, which probably reduced the dietary load of plant antinutrients. On the other hand, the present study clearly demonstrated how Atlantic salmon adjusted their metabolic functions in response to the dietary load of cholesterol. It has also expanded our understanding of sterol metabolism and turnover, adding to the existing, rather sparse, knowledge of these processes in fish. The results are outlined in the following sections and compared with the current understanding of sterol metabolism in humans and rodents when applicable.

\section{Intestinal cholesterol absorption}

Whole-body cholesterol homeostasis is maintained by the regulation of cholesterol absorption from the intestinal lumen, endogenous cholesterol biosynthesis, conversion of

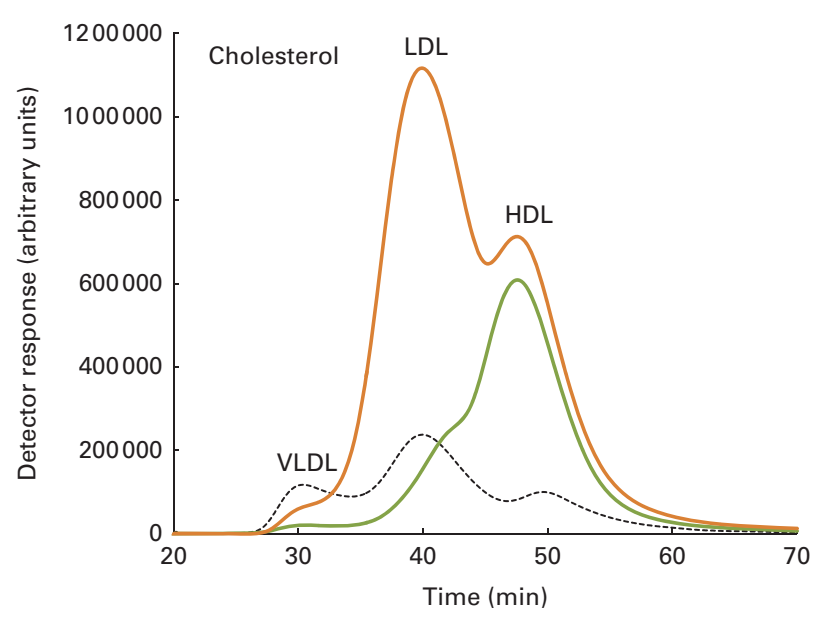

Fig. 3. Cholesterol lipoprotein profiles. A pooled sample of ten fish per diet group, control - and cholesterol — , as well as a human plasma sample ......, was used, and the elution peaks of the main lipoproteins are shown. 
Table 7. Differentially expressed genes involved in cell proliferation (hepatic microarray analysis)*

\begin{tabular}{|c|c|c|c|c|}
\hline GenBank accession & Name & Symbol & Fold change & $P \dagger$ \\
\hline 209154729 & DNA polymerase subunit $\alpha \mathrm{B}$ & pola2 & $-1 \cdot 74$ & 0.020 \\
\hline 209154823 & DNA replication licensing factor $\mathrm{mcm} 3$ & $\mathrm{mcm} 3$ & -2.35 & 0.046 \\
\hline 209735109 & DNA primase small subunit & prim1 & $-2 \cdot 05$ & 0.017 \\
\hline 221221503 & DNA-directed DNA polymerase $\varepsilon 3$ & pole3 & $-2 \cdot 00$ & 0.043 \\
\hline EG761395 & DNA ligase & lig & $-2 \cdot 33$ & 0.003 \\
\hline 89884249 & DNA replication licensing factor $\mathrm{mcm} 2$ & mcm2 & -2.43 & 0.030 \\
\hline 209731795 & Proliferating cell nuclear antigen & pcna & -1.79 & 0.015 \\
\hline EG791471 & Geminin DNA replication inhibitor & gmnn & -1.75 & 0.026 \\
\hline 209154227 & Ribonucleoside-diphosphate reductase subunit M2 & rrm2 & -1.99 & 0.034 \\
\hline 209156059 & Ribonucleoside-diphosphate reductase large subunit & $r r m 1$ & -2.93 & 0.004 \\
\hline 209735047 & Deoxycytidine kinase & dck & -2.50 & 0.005 \\
\hline 209735383 & Thymidylate synthase & tyms & $-2 \cdot 31$ & 0.016 \\
\hline 209737255 & XTP3-transactivated gene A protein homolog & xtp3a & $-2 \cdot 33$ & 0.012 \\
\hline DY737372 & Ribonucleoside-diphosphate reductase subunit M2 & rrm2 & $-2 \cdot 15$ & 0.038 \\
\hline BT046000 & Ribonucleoside-diphosphate reductase large subunit & rrm1 & $-2 \cdot 15$ & 0.040 \\
\hline 117444991 & Non-histone chromosomal protein $\mathrm{H} 6$ & hmgn2 & -1.98 & 0.002 \\
\hline 221219231 & Non-histone chromosomal protein $\mathrm{H} 6$ & hmgn2 & -1.80 & 0.006 \\
\hline 221220141 & Histone $\mathrm{H} 3$-like centromeric protein A & cenpa & $-2 \cdot 72$ & 0.019 \\
\hline 223647775 & Inner centromere protein B & incenp-b & -2.02 & 0.003 \\
\hline DY691889 & Lamin B receptor & $\operatorname{tm} 7 s f 2$ & $-3 \cdot 16$ & 0.012 \\
\hline DY722403 & WW domain-containing adapter protein & waca & -1.78 & 0.011 \\
\hline 209154017 & Histone chaperone asf1-A & $a s f 1 b b$ & -1.65 & 0.001 \\
\hline 209730641 & Borealin & cdca8 & -4.28 & 0.002 \\
\hline 223647855 & Condensin complex subunit 3 & ncapg & -2.76 & 0.021 \\
\hline ВT046289 & G2/mitotic-specific cyclin B1 & $c c n b 1$ & -3.80 & 0.004 \\
\hline 209734763 & Cell division control protein 2 homolog & $c d k 2$ & -3.61 & 0.004 \\
\hline 209730441 & G2/mitotic-specific cyclin B1 & $c c n b 1$ & $-3 \cdot 11$ & 0.002 \\
\hline 209147721 & Cell division cycle protein 20 homolog & cdc20 & -3.04 & 0.015 \\
\hline ВT072533 & G2/mitotic-specific cyclin B1 & ccnb1 & $-2 \cdot 87$ & 0.014 \\
\hline 209156219 & Regulator of cytokinesis 1 & prc1 & -1.84 & 0.002 \\
\hline 221221057 & Cyclin-dependent kinase 2-associated protein 1 & cdk2ap1 & -1.72 & 0.039 \\
\hline CB507021 & Cell division protein kinase 2 & cdk2 & -1.68 & 0.043 \\
\hline EG763566 & Cyclin L1 & $c c n / 1$ & 1.94 & 0.003 \\
\hline 209156243 & Tob1 & tob1 & $2 \cdot 10$ & 0.034 \\
\hline 209732103 & Cyclin-dependent kinase inhibitor $1 \mathrm{C}$ & $c d k n 1 c$ & 2.45 & 0.026 \\
\hline 221221565 & Spindle and kinetochore-associated protein 1 & ska1 & -3.86 & 0.012 \\
\hline 209731291 & Mitotic spindle assembly checkpoint protein & $\operatorname{mad} 2 / 1$ & $-3 \cdot 25$ & 0.002 \\
\hline 223647645 & Centromere protein $\mathrm{S}$ & cepns & -2.87 & 0.001 \\
\hline 209733735 & Centromere protein $\mathrm{N}$ & cenpn & $-2 \cdot 61$ & 0.003 \\
\hline 117570521 & Kif19 protein - Ident 36 & kif19 & -2.59 & 0.010 \\
\hline ВT058720 & Tubulin- $\beta-1$ chain & tubb1 & $-2 \cdot 15$ & 0.015 \\
\hline EG924886 & Kinesin-like protein kif7 - Ident 44 & kif7 & -2.09 & 0.015 \\
\hline CB514949 & Tubulin- $\beta-1$ chain & tubb1 & -2.04 & 0.037 \\
\hline CK990304 & Tubulin- $\alpha$ chain & tuba & -1.98 & 0.001 \\
\hline 223648221 & Tubulin- $\alpha-1 \mathrm{~A}$ chain & tuba1a & -1.97 & 0.012 \\
\hline EG850126 & Tubulin- $\alpha$ chain & tuba & -1.84 & $<0.001$ \\
\hline DY693701 & Mitotic-spindle organising protein 2 & $m z t 2$ & 1.69 & 0.042 \\
\hline 209154819 & Targeting protein for Xklp2 & tpx2 & -2.35 & 0.005 \\
\hline 209730617 & Baculoviral IAP repeat-containing protein 5 & birc5 & -1.94 & 0.003 \\
\hline EG923079 & Protein phosphatase 1 regulatory subunit $12 \mathrm{~A}$ & ppp1r12a & -2.67 & 0.041 \\
\hline 221221689 & Polyamine-modulated factor 1 & pmf1 & -2.06 & 0.011 \\
\hline
\end{tabular}

* Values are mean fold change observed in the cholesterol diet-fed group in comparison with those in the control diet-fed group.

$\dagger P$ values obtained in the $t$ test are given.

cholesterol into bile acids, and faecal excretion of bile. Although the liver has traditionally been considered to be the major site of control in the maintenance of cholesterol homeostasis, the importance of the intestine in many aspects of cholesterol physiology is increasingly recognised ${ }^{(44,45)}$. Cholesterol present in the intestinal lumen derives from several sources, including diet, bile, intestinal secretion and shed epithelial cells. The molecular mechanisms responsible for sterol uptake have not been completely defined, but the intestinal uptake of cholesterol and plant sterols is believed, at least partially, to be mediated by the NPC1L1 transporter ${ }^{(46)}$.
Cholesterol that is absorbed or synthesised locally in the enterocytes is thought to be either expelled into the intestinal lumen through the actions of the ATP-binding cassette ABCG5/ABCG8 heterodimeric transporter for eventual excretion via the faeces or esterified by the action of ACAT and packaged into chylomicrons for transport into the body ${ }^{(47)}$. In addition, the current literature indicates that cholesterol may be exported out to the basolateral compartment in HDL particles via the ABCA1 efflux pump ${ }^{(44,48)}$. The efflux of plant sterols from enterocytes back to the intestinal lumen is facilitated by $\mathrm{ABCG} 5 / \mathrm{Gr}^{(49)}$. In the present study, gene 
expression profiling indicated that the dietary load of cholesterol promoted the regulation of intracellular sterol levels in the intestine by reducing sterol uptake and inducing sterol efflux. First, the expression of $n p c 1 l 1$, presumably responsible for cholesterol uptake, was suppressed, whereas that of the apical $(a b c g 5)$ and the basolateral (abca1) efflux transporters was induced. Second, increased capacity for cholesterol esterification was indicated by the increased acat mRNA levels. In addition to cholesterol assembly into lipoproteins, cholesterol esterification may function as an intracellular buffering mechanism for the storage of FA sterol esters in lipid droplets. Cholesterol supplementation also seemed to abolish the intestinal uptake of plant sterols. The very low plasma levels of sitosterol and campesterol found in the fish fed the cholesterol-containing diet are likely to reflect a competition between cholesterol and the plant sterols in the intestine, as well as a result of alterations in sterol transport mechanisms ${ }^{(50)}$. In parallel to alterations in the expression of sterol transporters, we observed the differential expression of several nuclear receptors with important regulatory roles in lipid and sterol metabolism. Specifically, there was a decrease in the expression of srebp 2 after cholesterol supplementation, whereas the expression of $l x r$, srebp 1 and ppar $\alpha$ was induced. The induction of $l x r$ expression was not unexpected, as LXR is activated by oxysterols and is known to induce $\operatorname{abcg} 5 /$ abcg 8 and abca1 expression in mammals ${ }^{(51)}$. Additionally, SREBP2 is inactivated by high intracellular cholesterol levels ${ }^{(52)}$, and srebp2 has recently been reported as a master transcriptional regulator of cholesterol metabolism in Atlantic salmon ${ }^{(53)}$. The suppression of srebp 2 expression by the dietary load of cholesterol probably reflects the suppression of endogenous cholesterol biosynthesis, as outlined below. The induction of ppar $\alpha$ expression indicates a similar effect on cholesterol synthesis, as it is known that the activation of PPAR $\alpha$ decreases cholesterol synthesis by reduction of nuclear SREBP-2 levels ${ }^{(54)}$.

\section{Cholesterol transport in plasma}

Cholesterol and cholesteryl esters are transported in the blood in the form of lipoproteins. In mammals ${ }^{(26)}$, dietary cholesterol is transported from the intestine to the liver in the form of chylomicrons. In turn, hepatocytes secrete lipids in VLDL particles that are processed in the circulation into LDL, which deliver cholesterol to extrahepatic tissues. Finally, extrahepatic tissues can release excess cholesterol in HDL particles, which returns to the liver. In the present study, a pronounced change in the pattern and distribution of lipids in the plasma of fish fed the cholesterol-containing diet was observed, and the profile was found to be similar to the 'atherogenic' profile found in hypercholesterolaemic patients. CETP is a plasma protein that facilitates the transport of cholesteryl esters and TAG between lipoproteins. High-cholesterol diets induce both mRNA levels and activity of CETP in a wide range of mammalian species and probably facilitate the recycling of excess cholesterol deposited in extrahepatic tissues ${ }^{(55)}$. The present study demonstrated a similar mechanism in fish, as evidenced by the induction of cetp expression in fish fed the cholesterol-containing diet. Additionally, the expression of $l p l$ was induced, indicative of the selective uptake of cholesterol from the dominating lipoprotein fraction $\mathrm{LDL}^{(56)}$.

\section{Cholesterol and bile acid biosynthesis}

An obvious effect of cholesterol supplementation was the strong and concerted hepatic down-regulation of the expression of genes encoding nearly all enzymes involved in de novo cholesterol biosynthesis ${ }^{(52,57)}$, coinciding with the decrease in the expression of the master regulator $\operatorname{srebp} 2^{(58,59)}$. Furthermore, the expression of both $l x r$, recently reported to be regulated by oxysterols in rainbow trout ${ }^{(60)}$, and its obligate partner $r x r$ was induced by cholesterol supplementation. Gene expression data were further supported by the reduced plasma lathosterol levels in the cholesterolsupplemented group, as the circulating levels of this intermediate in cholesterol synthesis reflect whole-body cholesterol synthesis ${ }^{(61)}$. As lathosterol is transported in the same way as cholesterol and dependent on the same transporters, the pool of cholesterol will have some effect on the absolute levels. Thus, it is appropriate to assess the lathosterol:cholesterol ratio. Therefore, the suppression will be even more marked after correction for the cholesterol levels. Interestingly, bmgcr expression was not influenced by cholesterol supplementation. This is in contrast to the current understanding of HMGCR as the rate-controlling enzyme in cholesterol biosynthesis and therefore an important regulatory enzyme ${ }^{(59)}$. However, it should be emphasised that this enzyme is also regulated by post-translation mechanisms and that such mechanisms may be more important than the transcriptional mechanisms ${ }^{(57)}$ Based on its presumed key regulatory function in cholesterol synthesis, HMGCR has been a subject of targeted investigation in fish feeding trials and seems to be affected by cholesterol supplementation $^{(21)}$ or by hypocholesterolaemia induced by plant-based feed ${ }^{(8,14,62)}$. However, several microarray-based approaches have reported the differential expression of a wide range of cholesterol biosynthetic genes in response to plant-based feeding ${ }^{(24,53,63,64)}$. Thus, it seems likely that cholesterol synthesis in fish is regulated by the transcriptional control of most of the genes involved in the cholesterol biosynthetic pathway, similar to observations made in mammals ${ }^{(52,58)}$. The suppression of de novo cholesterol synthesis was also indicated by the induction of $a d b 3$ expression. This enzyme catalyses the oxidation of intermediary alcohols of the shunt pathway of mevalonate metabolism, which diverts about $5 \%$ of the production of mevalonate in the rat liver ${ }^{(43,65)}$

Biliary secretion of sterols, either as cholesterol or after conversion into bile salts, is the only significant mechanism for cholesterol removal from the body, and bile acids account for approximately $50 \%$ of the cholesterol lost in humans ${ }^{(66)}$. High dietary cholesterol levels are known to lead to increased synthesis of bile acids in rodents but not in humans, in whom reduction in the intestinal absorption of cholesterol seems to be the main regulatory mechanism ${ }^{(51,67)}$. In mice, the cholesterol-induced increase in bile acid synthesis has been shown to involve an LXR-mediated induction of the rate-limiting 
Table 8. Differentially expressed genes involved in immunity (hepatic microarray analysis)*

\begin{tabular}{|c|c|c|c|c|}
\hline GenBank accession & Name & Symbol & Fold change & $P \dagger$ \\
\hline DW536799 & Complement C1q-like protein 2 & c1ql2 & 4.14 & 0.003 \\
\hline CA038278 & Complement $\mathrm{C} 1 \mathrm{q}$-like protein 4 precursor & c1ql4 & 3.51 & 0.040 \\
\hline CX356308 & Complement $\mathrm{C} 1 \mathrm{q}$ subcomponent subunit $\mathrm{C}$ & $c 1 q c$ & 3.14 & $<0.001$ \\
\hline CK889126 & Complement C1q-like protein 4 & c1ql4 & 1.95 & 0.009 \\
\hline CB509933 & Complement factor $\mathrm{H}$ precursor & cfhl1 & 1.71 & 0.046 \\
\hline 223672506 & High-affinity Ig receptor subunit- $\gamma$ & fcer1g & 1.92 & 0.032 \\
\hline BG934838 & Differentially regulated trout protein 1 & & $2 \cdot 81$ & 0.049 \\
\hline 209733731 & Lysozyme C II precursor & lyz2 & 2.02 & 0.025 \\
\hline 209156091 & MMP 13 or collagenase 3 & mmp13 & 3.07 & 0.013 \\
\hline 223647567 & Neutrophil cytosolic factor 1 & ncfi & 2.32 & 0.044 \\
\hline 209154611 & Immediate early response $2-2$ & & 1.89 & 0.002 \\
\hline BT048895 & NF-кB inhibitor- $\alpha$ & nfkbia & 1.76 & 0.008 \\
\hline DW537446 & Chitinase & chia & -1.98 & 0.029 \\
\hline CK895552 & Leukocyte cell-derived chemotaxin 2-1 & lect2I & -3.39 & 0.026 \\
\hline 117545301 & Leukocyte cell-derived chemotaxin 2-2 & lect2-2 & -4.60 & 0.017 \\
\hline CN442491 & Leukocyte cell-derived chemotaxin 2-3 & lect2-3 & $-6 \cdot 18$ & 0.011 \\
\hline
\end{tabular}

* Values are mean fold change observed in the cholesterol diet-fed group in comparison with those in the control diet-fed group. $\dagger P$ values obtained in the $t$ test are given.

enzyme in bile acid synthesis, CYP7A1 ${ }^{(68)}$. In accordance with this, in the present study, increased hepatic mRNA levels of $l x r$ and markedly increased levels of cyp $7 a 1$ were observed, suggesting a similar mechanism. Increased CYP7A1 enzymatic activity after dietary cholesterol treatment has also been reported in previous fish studies ${ }^{(15,21)}$. C4 is an intermediate in bile acid synthesis, and the plasma level of this oxysterol has been shown to be a marker of bile acid synthesis in humans ${ }^{(42)}$. It seems likely that this is also the case in fish, but to our knowledge this has not been studied previously. Plasma C4 levels in the control fish were low, lower than the corresponding levels in the mouse and man. However, C4 levels in the cholesterol-supplemented group were considerably higher, reflecting the markedly increased synthesis of bile acids as a consequence of the dietary load of cholesterol. In support of this, it was also observed that the levels of the precursor of $\mathrm{C} 4,7 \alpha$-hydroxycholesterol, were increased in the plasma of fish fed the cholesterol-containing diet. There was a very high correlation between $\mathrm{C} 4$ and $7 \alpha$-hydroxycholesterol levels ( $r$ 0.96). It should be emphasised that the circulating levels of $\mathrm{C} 4$ and oxysterols are to some extent affected by the size of the pool of cholesterol in plasma. In view of this, it would be appropriate to compare the C4:oxysterol:cholesterol ratio rather than the absolute levels. Even after such a 'correction', the plasma levels of C4 and $7 \alpha$-hydroxycholesterol were still much higher in the cholesterol-supplemented group, reflecting the high bile acid synthesis. The major pathway for bile acid synthesis in mammals, and most probably also in fish, involves CYP7A1 as a rate-limiting and highly regulated enzyme. In addition, there is a minor pathway (the alternative or acid pathway) involving 27-hydroxylation as the first and rate-liming step ${ }^{(69)}$. This enzyme is not regulated to the same extent as CYP7A1, at least not in mammals ${ }^{(70)}$. The levels of 27-hydroxycholesterol in the circulation may reflect the activity of this pathway. Dietary cholesterol supplementation increased the plasma levels of 27-hydroxycholesterol as well as hepatic mRNA levels of cyp27a1, suggesting that this pathway for bile acid formation was also stimulated. However, most probably, this increase is secondary to the increased carrier function with high levels of cholesterol, and the 27-hydroxycholesterol:cholesterol ratio was not increased. Increased bile salt production was also indicated by the large negative $\mathrm{AD}$ of taurine as well as the induced expression of the taurine transporter slc $6 a \sigma$ in both the liver and intestine. Taken together, these findings strongly suggest that the dietary load of cholesterol resulted in decreased cholesterol synthesis as well as hepatic conversion of excess cholesterol into bile acids. The increased hepatic synthesis of bile acids in fish fed the cholesterol-containing diet was, however, not reflected in total bile acid levels or total conjugated bile acid levels in the gall bladder. The taurine-conjugated bile acids were the predominant form of bile acids found in the bile, with taurocholic acid being the predominant individual bile acid. This is in accordance with previous reports on salmonid bile composition ${ }^{(71,72)}$. While no diet effect on taurocholic acid levels was observed, taurochenodeoxycholic acid levels were higher in the bile of fish fed the cholesterol-containing diet, and unconjugated cholic acid levels were also significantly increased. Further studies using isotope-labelled cholesterol should be conducted to quantify the rate of cholesterol conversion into bile acids.

\section{Effects of dietary cholesterol supplementation on fat metabolism and other cellular functions}

The marked reduction in plasma TAG levels in fish fed the cholesterol-containing diet is in accordance with observations made in hypercholesterolaemic mice ${ }^{(73)}$ and indicates that cholesterol and/or its metabolites are involved in the regulation of TAG metabolism in salmon. No effects were observed on the intestinal expression levels of genes related to lipid uptake and transport, except for a decrease in cd36 expression. However, CD36 has also been suggested to be involved in cholesterol uptake from the intestinal lumen in mammals ${ }^{(74)}$. Similarly, in the liver, the main responses related to lipid metabolism were, most probably, directly caused by 
the dietary load of cholesterol (apo-L3 (apo L3), apo-AIV (apo AIV) and $(p l)$. The TAG biosynthetic pathway was not affected, with the exception of a 2-fold induction of 1-acyl-sn-glycerol3-phosphate acyltransferase- $\gamma$ (agpat3) expression, which could be a response to the decreased plasma TAG levels. The hepatic gene expression data suggested a decrease in cell proliferation, but neither fish growth nor organ indices were affected. It is possible that the cholesterol-enriched diet induced hypertrophic growth of the liver. Cholesterol supplementation also seemed to affect the non-specific immune system by the up-regulation of the expression of several complement genes. Corresponding observations have been made in rainbow trout, showing that dietary cholesterol supplementation increased the activity of the alternative complement pathway and several other non-specific immune parameters $^{(23)}$

\section{Conclusions}

Cholesterol supplementation to a plant-based diet did not affect the growth, organ weights, or intestinal and hepatic histomorphology of Atlantic salmon. On the other hand, dietary cholesterol supplementation seemed to promote the induction of sterol efflux by enterocytes, whereas sterol uptake from the intestine was suppressed. In the liver, the synthesis of cholesterol decreased correspondingly and conversion into bile acids increased. The marked effect of cholesterol supplementation on bile acid synthesis suggests that dietary cholesterol can be used to increase bile acid synthesis in fish. However, the dietary load of cholesterol used in the present study was very high, and it would be of interest to study the effect of considerably lower dietary levels.

\section{Supplementary material}

To view supplementary material for this article, please visit http://dx.doi.org/10.1017/S0007114514000373

\section{Acknowledgements}

The present paper reports the results of contract research mainly funded by BioMar A/S under the leadership of senior scientist Kjell Måsøval. The Aquaculture Protein Centre (APC) at the NVH, a centre of excellence under the Norwegian Research Council (project no. 145949/120), was the main scientific partner of the experiment. The molecular part of the experiment was funded by the APC. The authors thank the senior researcher Gerd Marit Berge and technicians at the Nofima research station at Sunndalsøra, Norway, for skilful animal care and scientific follow-up and APC's technicians Ellen K. Hage, Elin C. Valen and Gunn C. Østby for their excellent technical assistance.

The authors' contributions are as follows: T. M. K. performed the molecular analysis and analysed the data and wrote the manuscript; I. B. was responsible for the biochemical analysis and manuscript revision, A. K. and G. T. participated in the microarray analyses and revised the manuscript; A. K. designed and conducted the feeding trial and coordinated the research.

None of the authors has any conflicts of interest to declare.

\section{References}

1. Naylor RL, Hardy RW, Bureau DP, et al. (2009) Feeding aquaculture in an era of finite resources. Proc Natl Acad Sci US A 106, 15103-15110.

2. Tacon AGJ (2011) Demand and supply of feed ingredients for farmed fish and crustaceans: trends and prospects. In FAO Fisheries and Aquaculture Technical Paper No 564, 87 pp. Rome: FAO.

3. Gatlin DM, Barrows FT, Brown P, et al. (2007) Expanding the utilization of sustainable plant products in aquafeeds: a review. Aquacult Res 38, 551-579.

4. Krogdahl A, Penn M, Thorsen J, et al. (2010) Important antinutrients in plant feedstuffs for aquaculture: an update on recent findings regarding responses in salmonids. Aquacult Res 41, 333-344.

5. Tocher DR, Bendiksen EA, Campbell PJ, et al. (2008) The role of phospholipids in nutrition and metabolism of teleost fish. Aquaculture 280, 21-34.

6. Francis G, Makkar HPS \& Becker K (2001) Antinutritional factors present in plant-derived alternate fish feed ingredients and their effects in fish. Aquaculture 199, 197-227.

7. Kaushik SJ, Cravedi JP, Lalles JP, et al. (1995) Partial or total replacement of fishmeal by soybean protein on growth, protein utilization, potential estrogenic or antigenic effects, cholesterolemia and flesh quality in rainbow trout, Oncorbynchus mykiss. Aquaculture 133, 257-274.

8. Kortner TM, Gu J, Krogdahl ^, et al. (2013) Transcriptional regulation of cholesterol and bile acid metabolism after dietary soybean meal treatment in Atlantic salmon, Salmo salar L. BrJ Nutr 109, 593-604

9. Krogdahl ^, Bakke-McKellep AM \& Baeverfjord G (2003) Effects of graded levels of standard soybean meal on intestinal structure, mucosal enzyme activities, and pancreatic response in Atlantic salmon (Salmo salar L.). Aquacult Nutr 9, 361-371.

10. Regost C, Arzel J \& Kaushik SJ (1999) Partial or total replacement of fish meal by corn gluten meal in diet for turbot (Psetta maxima). Aquaculture 180, 99-117.

11. Romarheim OH, Skrede A, Penn M, et al. (2008) Lipid digestibility, bile drainage and development of morphological intestinal changes in rainbow trout (Oncorbynchus mykiss) fed diets containing defatted soybean meal. Aquaculture 274, 329-338

12. Yamamoto T, Suzuki N, Furuita H, et al. (2007) Supplemental effect of bile salts to soybean meal-based diet on growth and feed utilization of rainbow trout Oncorbynchus mykiss. Fish Sci 73, 123-131.

13. Maita M, Satoh K, Fukuda Y, et al. (1998) Correlation between plasma component levels of cultured fish and resistance to bacterial infection. Fish Pathol 33, 129-133.

14. Maita M, Maekawa J, Satoh K, et al. (2006) Disease resistance and hypocholesterolemia in yellowtail Seriola quinqueradiata fed a non-fishmeal diet. Fish Sci 72, 513-519.

15. Yun BA, Mai KS, Zhang WB, et al. (2011) Effects of dietary cholesterol on growth performance, feed intake and cholesterol metabolism in juvenile turbot (Scophthalmus maximus L.) fed high plant protein diets. Aquaculture 319, 105-110.

16. Bjerkeng B, Storebakken T \& Wathne E (1999) Cholesterol and short-chain fatty acids in diets for Atlantic 
salmon Salmo salar (L.): effects on growth, organ indices, macronutrient digestibility, and fatty acid composition. Aquacult Nutr 5, 181-191.

17. Sealey WM, Craig SR \& Gatlin DM (2001) Dietary cholesterol and lecithin have limited effects on growth and body composition of hybrid striped bass (Morone chrysops $\times M$. saxatilis). Aquacult Nutr 7, 25-31.

18. Deng J, Mai K, Ai Q, et al. (2010) Interactive effects of dietary cholesterol and protein sources on growth performance and cholesterol metabolism of Japanese flounder (Paralichthys olivaceus). Aquacult Nutr 16, 419-429.

19. Twibell RG \& Wilson RP (2004) Preliminary evidence that cholesterol improves growth and feed intake of soybean meal-based diets in aquaria studies with juvenile channel catfish, Ictalurus punctatus. Aquaculture 236, 539-546.

20. Yun BA, Ai Q, Mai K, et al. (2012) Synergistic effects of dietary cholesterol and taurine on growth performance and cholesterol metabolism in juvenile turbot (Scophthalmus maximus L.) fed high plant protein diets. Aquaculture 324-325, 85-91.

21. Deng J, Bi B, Kang B, et al. (2013) Improving the growth performance and cholesterol metabolism of rainbow trout (Oncorbynchus mykiss) fed soyabean meal-based diets using dietary cholesterol supplementation. Br J Nutr 110, 29-39.

22. Rios-Duran MG, Valencia IR, Ross LG, et al. (2013) Nutritional evaluation of autoclaved Salicornia bigelovii Torr. seed meal supplemented with varying levels of cholesterol on growth, nutrient utilization and survival of the Nile tilapia (Oreochromis niloticus). Aquacult Int 21, 1355-1371.

23. Deng JM, Kang B, Tao LL, et al. (2013) Effects of dietary cholesterol on antioxidant capacity, non-specific immune response, and resistance to Aeromonas bydrophila in rainbow trout (Oncorbynchus mykiss) fed soybean meal-based diets. Fish Shellfish Immunol 34, 324-331.

24. Geay F, Ferraresso S, Zambonino-Infante JL, et al. (2011) Effects of the total replacement of fish-based diet with plant-based diet on the hepatic transcriptome of two European sea bass (Dicentrarchus labrax) half-sibfamilies showing different growth rates with the plant-based diet. $B M C$ Genomics 12, 522-539.

25. Vilhelmsson OT, Martin SAM, Medale F, et al. (2004) Dietary plant-protein substitution affects hepatic metabolism in rainbow trout (Oncorbynchus mykiss). Br J Nutr 92, 71-80.

26. Ikonen E (2008) Cellular cholesterol trafficking and compartmentalization. Nat Rev Mol Cell Biol 9, 125-138.

27. Committee on the Nutrient Requirements of Fish and Shrimp \& National Research Council (2011) Nutrient Requirements of Fish and Shrimp. Washington, DC: National Academies Press.

28. Krasnov A, Timmerhaus G, Afanasyev S, et al. (2011) Development and assessment of oligonucleotide microarrays for Atlantic salmon (Salmo salar L.). Comp Biochem Physiol D 6, 31-38.

29. Bustin SA, Benes V, Garson JA, et al. (2009) The MIQE guidelines: minimum information for publication of quantitative real-time PCR experiments. Clin Chem 55, 611-622.

30. Kortner TM, Valen EC, Kortner H, et al. (2011) Candidate reference genes for quantitative real-time PCR (qPCR) assays during development of a diet-related enteropathy in Atlantic salmon (Salmo salar L.) and the potential pitfalls of uncritical use of normalization software tools. Aquaculture 318, 355-363.

31. Livak KJ \& Schmittgen TD (2001) Analysis of relative gene expression data using real-time quantitative PCR and the $2(-\Delta \Delta C(T))$ method. Methods 25, 402-408.
32. Refstie S, Helland SJ \& Storebakken T (1997) Adaptation to soybean meal in diets for rainbow trout. Oncorbynchus mykiss. Aquaculture 153, 263-272.

33. Mason ME \& Waller GR (1964) Dimethoxypropane induced transesterification of fats and oils in preparation of methyl esters for gas chromatographic analysis. Anal Chem 36, $583-586$.

34. Hoshi M, Williams M \& Kishimoto Y (1973) Esterification of fatty acids at room temperature by chloroform-methanolic HCl-cupric acetate. J Lipid Res 14, 599-601.

35. Tagliacozzi D, Mozzi AF, Casetta B, et al. (2003) Quantitative analysis of bile acids in human plasma by liquid chromatography-electrospray tandem mass spectrometry: a simple and rapid one-step method. Clin Chem Lab Med 41, 1633-1641.

36. Björkhem I \& Falk O (1983) Assay of the major bile acids in serum by isotope dilution-mass spectrometry. Scand J Clin Lab Invest 43, 163-170.

37. Dzeletovic S, Breuer O, Lund E, et al. (1995) Determination of cholesterol oxidation products in human plasma by isotope dilution-mass spectrometry. Anal Biochem 225, 73-80.

38. Acimovic J, Lovgren-Sandblom A, Monostory K, et al. (2009) Combined gas chromatographic/mass spectrometric analysis of cholesterol precursors and plant sterols in cultured cells. J Chromatogr B Analyt Technol Biomed Life Sci 877 , 2081-2086.

39. Lund E, Sisfontes L, Reihner E, et al. (1989) Determination of serum levels of unesterified lathosterol by isotope dilutionmass spectrometry. Scand J Clin Lab Invest 49, 165-171.

40. Lövgren-Sandblom A, Heverin M, Larsson H, et al. (2007) Novel LC-MS/MS method for assay of 7alpha-hydroxy-4cholesten-3-one in human plasma. Evidence for a significant extrahepatic metabolism. J Chromatogr B Analyt Technol Biomed Life Sci 856, 15-19.

41. Parini P, Johansson L, Broijersén A, et al. (2006) Lipoprotein profiles in plasma and interstitial fluid analyzed with an automated gel-filtration system. Eur J Clin Invest 36, 98-104.

42. Axelson M, Björkhem I, Reihnér E, et al. (1991) The plasma level of 7 alpha-hydroxy-4-cholesten-3-one reflects the activity of hepatic cholesterol 7 alpha-hydroxylase in man. FEBS Lett 284, 216-218.

43. Keung WM (1991) Human liver alcohol dehydrogenases catalyze the oxidation of the intermediary alcohols of the shunt pathway of mevalonate metabolism. Biochem Biophys Res Commun 174, 701-707.

44. van der Wulp MY, Verkade HJ \& Groen AK (2013) Regulation of cholesterol homeostasis. Mol Cell Endocrinol 368, 1-16.

45. Wang DQ (2007) Regulation of intestinal cholesterol absorption. Annu Rev Physiol 69, 221-248.

46. Davis HR Jr, Zhu LJ, Hoos LM, et al. (2004) Niemann-Pick C1 Like 1 (NPC1L1) is the intestinal phytosterol and cholesterol transporter and a key modulator of whole-body cholesterol homeostasis. J Biol Chem 279, 33586-33592.

47. Brunham LR, Kruit JK, Iqbal J, et al. (2006) Intestinal ABCA1 directly contributes to HDL biogenesis in vivo. J Clin Invest 116, 1052-1062.

48. Hui DY, Labonte ED \& Howles PN (2008) Development and physiological regulation of intestinal lipid absorption. III. Intestinal transporters and cholesterol absorption. Am J Physiol Gastrointest Liver Physiol 294, G839-G843.

49. Calpe-Berdiel L, Escola-Gil JC \& Blanco-Vaca F (2009) New insights into the molecular actions of plant sterols and stanols in cholesterol metabolism. Atherosclerosis 203, 18-31.

50. Liland NS, Espe M, Rosenlund G, et al. (2013) High levels of dietary phytosterols affect lipid metabolism and increase 
liver and plasma TAG in Atlantic salmon (Salmo salar L.). $\mathrm{Br}$ J Nutr 110, 1958-1967.

51. Kalaany NY \& Mangelsdorf DJ (2006) LXRs and FXR: the yin and yang of cholesterol and fat metabolism. Ann Rev Physiol 68, 159-191.

52. Horton JD, Goldstein JL \& Brown MS (2002) SREBPs: activators of the complete program of cholesterol and fatty acid synthesis in the liver. J Clin Invest 109, 1125-1131.

53. Leaver MJ, Villeneuve LAN, Obach A, et al. (2008) Functional genomics reveals increases in cholesterol biosynthetic genes and highly unsaturated fatty acid biosynthesis after dietary substitution of fish oil with vegetable oils in Atlantic salmon (Salmo salar). BMC Genomics 9, 299.

54. Konig B, Koch A, Spielmann J, et al. (2007) Activation of PPARalpha lowers synthesis and concentration of cholesterol by reduction of nuclear SREBP-2. Biochem Pharmacol 73, 574-585.

55. Tall AR (1993) Plasma cholesteryl ester transfer protein. J Lipid Res 34, 1255-1274.

56. Merkel M, Heeren J, Dudeck W, et al. (2002) Inactive lipoprotein lipase (LPL) alone increases selective cholesterol ester uptake in vivo, whereas in the presence of active LPL it also increases triglyceride hydrolysis and whole particle lipoprotein uptake. J Biol Chem 277, 7405-7411.

57. Goldstein JL, DeBose-Boyd RA \& Brown MS (2006) Protein sensors for membrane sterols. Cell 124, 35-46.

58. Sakakura Y, Shimano H, Sone H, et al. (2001) Sterol regulatory element-binding proteins induce an entire pathway of cholesterol synthesis. Biochem Biophys Res Comm 286, 176-183.

59. Brown MS \& Goldstein JL (1997) The SREBP pathway: regulation of cholesterol metabolism by proteolysis of a membrane-bound transcription factor. Cell 89, 331-340.

60. Cruz-Garcia L, Sanchez-Gurmaches J, Gutierrez J, et al. (2011) Regulation of LXR by fatty acids, insulin, growth hormone and tumor necrosis factor- $\alpha$ in rainbow trout myocytes. Comp Biochem Physiol A Mol Integr Physiol 160, 125-136.

61. Kempen HJM, Glatz JFC, Leuven JAG, et al. (1988) Serum lathosterol concentration is an indicator of whole-body cholesterol synthesis in humans. J Lipid Res 29, 1149-1155.

62. Gu M, Kortner TM, Penn M, et al. (2013) Effects of dietary plant meal and soya-saponin supplementation on intestinal and hepatic lipid droplet accumulation and lipoprotein and sterol metabolism in Atlantic salmon (Salmo salar L.). Br J Nutr 111, 432-444.

63. Panserat S, Hortopan GA, Plagnes-Juan E, et al. (2009) Differential gene expression after total replacement of dietary fish meal and fish oil by plant products in rainbow trout (Oncorbynchus mykiss) liver. Aquaculture 294, 123-131.

64. Morais S, Taggart JB, Guy DR, et al. (2012) Hepatic transcriptome analysis of inter-family variability in flesh n-3 longchain polyunsaturated fatty acid content in Atlantic salmon. BMC Genomics 13, 410.

65. Weinstock SB, Kopito RR, Endemann G, et al. (1984) The shunt pathway of mevalonate metabolism in the isolated perfused-rat-liver. J Biol Chem 259, 8939-8944.

66. Repa JJ \& Mangelsdorf DJ (1999) Nuclear receptor regulation of cholesterol and bile acid metabolism. Curr Opin Biotechnol 10, 557-563.

67. Spady DK \& Cuthbert JA (1992) Regulation of hepatic sterol metabolism in the rat. Parallel regulation of activity and messenger mRNA for 7-alpha-hydroxylase but not 3-hydroxy-3-methylglutaryl-coenzyme A reductase or low density lipoprotein receptor. J Biol Chem 267, 5584-5591.

68. Peet DJ, Turley SD, Ma WZ, et al. (1998) Cholesterol and bile acid metabolism are impaired in mice lacking the nuclear oxysterol receptor LXR alpha. Cell 93, 693-704.

69. Russell DW (2003) The enzymes, regulation, and genetics of bile acid synthesis. Ann Rev Biochem 72, 137-174.

70. Bjorkhem I, Araya Z, Rudling M, et al. (2002) Differences in the regulation of the classical and the alternative pathway for bile acid synthesis in human liver. No coordinate regulation of CYP7A1 and CYP27A1. J Biol Chem 277, 26804-26807.

71. Bogevik AS, Tocher DR, Langmyhr E, et al. (2009) Atlantic salmon (Salmo salar) postsmolts adapt lipid digestion according to elevated dietary wax esters from Calanus finmarchicus. Aquacult Nutr 15, 94-103.

72. Denton JE \& Yousef MK (1974) Bile acid composition of rainbow trout, Salmo gairdneri. Lipids 9, 945-951.

73. Obama T, Nagaoka S, Akagi K, et al. (2011) Dietary cholesterol reduces plasma triacylglycerol in apolipoprotein E-null mice: suppression of lipin-1 and -2 in the glycerol-3-phosphate pathway. PLoS One 6, e22917.

74. Nauli AM, Nassir F, Zheng S, et al. (2006) CD36 is important for chylomicron formation and secretion and may mediate cholesterol uptake in the proximal intestine. Gastroenterology 131, 1197-1207. 